\title{
Growth/Differentiation Factor-15 (GDF-15): From Biomarker to Novel Targetable Immune Checkpoint
}

\begin{abstract}
Jörg Wischhusen ${ }^{1 *}$, Ignacio Melero ${ }^{2,3,4}$ and Wolf Herman Fridman ${ }^{5}$
${ }^{1}$ Experimental Tumor Immunology, Department of Obstetrics and Gynecology, University of Würzburg Medical School, Würzburg, Germany, ${ }^{2}$ Program of Immunology and Immunotherapy, Center for Applied Medical Research (CIMA), Pamplona, Spain, ${ }^{3}$ Centro de Investigación Biomédica en Red Cáncer, CIBERONC, Madrid, Spain, ${ }^{4}$ Immunology and Immunotherapy Unit, Clínica Universidad de Navarra, Pamplona, Spain, ${ }^{5}$ INSERM, UMR_S 1138, Cordeliers Research Center, Université de Paris, Sorbonne Université Team Cancer, Immune Control and Escape, Paris, France
\end{abstract}

Growth/differentiation factor-15 (GDF-15), also named macrophage inhibitory cytokine-1, is a divergent member of the transforming growth factor $\beta$ superfamily. While physiological expression is barely detectable in most somatic tissues in humans, GDF-15 is abundant in placenta. Elsewhere, GDF-15 is often induced under stress conditions, seemingly to maintain cell and tissue homeostasis; however, a moderate increase in GDF-15 blood levels is observed with age. Highly elevated GDF-15 levels are mostly linked to pathological conditions including inflammation, myocardial ischemia, and notably cancer. GDF-15 has thus been widely explored as a biomarker for disease prognosis. Mechanistically, induction of anorexia via the brainstem-restricted GDF-15 receptor GFRAL (glial cell-derived neurotrophic factor [GDNF] family receptor $\alpha$-like) is welldocumented. GDF-15 and GFRAL have thus become attractive targets for metabolic intervention. Still, several GDF-15 mediated effects (including its physiological role in pregnancy) are difficult to explain via the described pathway. Hence, there is a clear need to better understand non-metabolic effects of GDF-15. With particular emphasis on its immunomodulatory potential this review discusses the roles of GDF-15 in pregnancy and in pathological conditions including myocardial infarction, autoimmune disease, and specifically cancer. Importantly, the strong predictive value of GDF-15 as biomarker may plausibly be linked to its immune-regulatory function. The described associations and mechanistic data support the hypothesis that GDF-15 acts as immune checkpoint and is thus an emerging target for cancer immunotherapy.

Keywords: growth/differentiation factor-15 (GDF-15), macrophage inhibitory cytokine-1 (MIC-1), cancer, pregnancy, autoimmunity, anorexia, immune exclusion, immunotherapy

\section{INTRODUCTION}

Growth/differentiation factor 15 (GDF-15) is also known as macrophage inhibitory cytokine (MIC)-1, non-steroidal anti-inflammatory drug-inducible gene (NAG)-1, placental transforming growth factor-beta (pTGFB), prostate-derived factor (PDF), and placental bone morphogenetic protein (PLAB). GDF-15 is a divergent member of the transforming growth factor- $\beta$ (TGF- $\beta$ ) superfamily (1-3). It contains seven conserved cysteine residues forming a cysteine knot that is the defining hallmark of the TGF- $\beta$ superfamily. 
Among all superfamily members, orthologous GDF-15 molecules show the lowest sequence conservation across species. While mature rat, mouse and human TGF- $\beta 1$ and BMP- 2 proteins are $99-100 \%$ sequence identical between species, homology is below $70 \%$ for GDF-15 (4). Moreover, promoter regions are entirely different between humans and mice (5).

Outside reproductive organs, GDF-15 shows low to absent constitutive expression; however, in many cell types it can be induced under stress conditions. The 308 amino acid chain comprises a signal peptide (29 amino acids), a pro-domain (167 amino acids) and the mature GDF-15 of 112 amino acids. While intracellular proteolytic processing is possible, GDF-15 is mostly secreted as pro-protein, and the pro-domain remains attached to the extracellular matrix (ECM). Thus, latent stromal stores are formed, enabling a rapid release of significant amounts of GDF-15 upon proteolytic cleavage (6). The pro-domain which remains in the ECM can be stained like a surface protein and has thus become the preferred target for immunohistochemical detection of GDF-15. Activation of GDF-15 is thought to be mainly mediated by furin (PCSK3) and other proprotein convertases of the subtilisin/kexin type, namely PCSK 5 and 6, which all cleave GDF-15 at the furine-like cleavage site RXXR (7). In placental cytotrophoblasts, processing and maturation can also occur via matrix metalloproteinase (MMP)-26 (8). Cleavage by membrane-type 1-matrix metalloproteinase (MT1MMP), in contrast, abrogated autocrine effects in cancer cells (9). Interestingly, GDF-15 can also be detected in the nucleus, where it was reported to inhibit the Smad pathway by Smad complex disruption (10). Once fully processed, GDF-15 is released as a mature homodimer, with both molecules held together by a disulfide bond (11). Due to its low molecular weight $(25 \mathrm{kD}$ per dimer), mature GDF-15 is subject to renal clearance with a half-life of about $3 \mathrm{~h}$ in humans (12).

In healthy individuals, GDF-15 expression is by far most prominent in the placenta, followed by the prostate where both androgens and calcitriol (a Vitamin D metabolite) have been shown to regulate GDF-15 (13). Low levels of expression have been observed in the bladder, kidney, colon, stomach, liver, gall bladder, pancreas, and endometrium $(11,14)$. Cell types shown to express GDF-15 include cardiomyocytes, adipocytes, macrophages, endothelial and vascular smooth muscle cells both in healthy and diseased tissues [review by Tsai et al. (15)]. Being a stress-inducible cytokine, GDF-15 is (up-)regulated by several inflammatory or stress-related proteins such as interleukin (IL)-1ß, tumor necrosis factor (TNF)$\alpha$, interleukin-2, and macrophage colony-stimulating factor (MCSF)-1, suggesting a complex and tissue-specific regulation (16). Medication, cell stress and local interruption of blood supply can also induce GDF-15 during surgical procedures (17), which may contribute to the frequently elevated GDF15 mRNA expression in surgical specimens. Still, in most tissues that can show inducible GDF-15 expression, physiological GDF-15 levels are low to absent in healthy individuals (14). Moreover, an all-male twin study revealed a significantly lower rate of survival for twins with elevated GDF-15 levels, with an odds ratio of 3.38 for death within 14 years (95\%CI: 1.38 8.26) (18).
GDF-15 knock-out mice are viable and do not show any obvious phenotype after birth. A mild ( $\leq 20 \%)$ progressive loss of motor axons and rotarod motor skills are observed at 6 months suggesting a role for GDF-15 as a neurotrophic factor for motor and sensory neurons (19).

Elevated GDF-15 levels in cancer patients have been frequently reported. In a microarray-based study comparing 150 carcinomas from 10 anatomic sites of origin with 46 normal tissues derived from the corresponding tissues of tumor origin and other control non-transformed tissues, GDF-15 showed the highest level of tumor-associated (over)expression. Sera from patients with metastatic prostate, breast, and colorectal carcinomas validate this finding at protein level, which indicate that GDF-15 may be a biomarker for cancer (20). Cancer pathology specimens from the Protein Atlas database further confirmed elevated expression of GDF-15 in various types of cancer, most prominently in the prostate, urothelial, renal, melanoma, and colorectal cancers and, at relatively lower levels, in cervical, breast, endometrial, thyroid, and pancreatic cancers (21). Likewise, gene expression data from The Cancer Genome Atlas (TCGA) database show highest GDF-15 levels in prostate cancer and reveal also mRNA overexpression in breast, liver, colorectal, cervical, renal cell, hepato-, and cholangiocellular carcinomas $(22,23)$.

The numerous reported effects ascribed to GDF-15 in diverse malignancies (including intracranial brain tumors, melanoma, lung, gastrointestinal, pancreatic, colorectal, prostate, and breast epithelial cancers) include links between GDF-15 and tumorigenesis, disease progression, prognosis, clinical outcome and response to chemo- and radiotherapy $(24,25)$. Unfortunately, recombinant material sold by major distributors contained relevant amounts of TGF- $\beta$. This potential confounding factor has been described by several authors $(15,26,27)$, and independently observed by Pierre Coulie (personal communication) and in our own unpublished experiments. Thus, use of contaminated GDF-15 has been a common problem, which has likely affected a substantial number of investigations in this field. Thus, the definitive role of GDF-15 in cancer and its possible role in immunotherapy remain to be elucidated.

GDF-15 was recently shown to signal through glial cellderived neurotrophic factor (GDNF) family receptor $\alpha$-like (GFRAL). GFRAL, which is distantly related to the TGF- $\beta$ receptor family, is a neuronal high-affinity receptor for GDF15 (28, 29). GFRAL is exclusively expressed in the human brain stem and is responsible for GDF-15 mediated anorexia $(30,31)$. However, anorexia and cachexia that should be caused by GDF-15-dependent activation of GFRAL are typically not observed during pregnancy, despite highly elevated GDF-15 serum levels. It also remains to be determined whether the effects of induced GDF-15 expression in pathological conditions such as metabolic diseases, tissue injury, inflammation, and cancer, all depend on GFRAL. Given that physiological effects of GDF15 comprise manifold actions on cell types without detectable GFRAL expression, GFRAL-independent effects of GDF-15 appear plausible. This, in turn, leaves room for interactions between GDF-15 and yet unidentified receptor systems. 


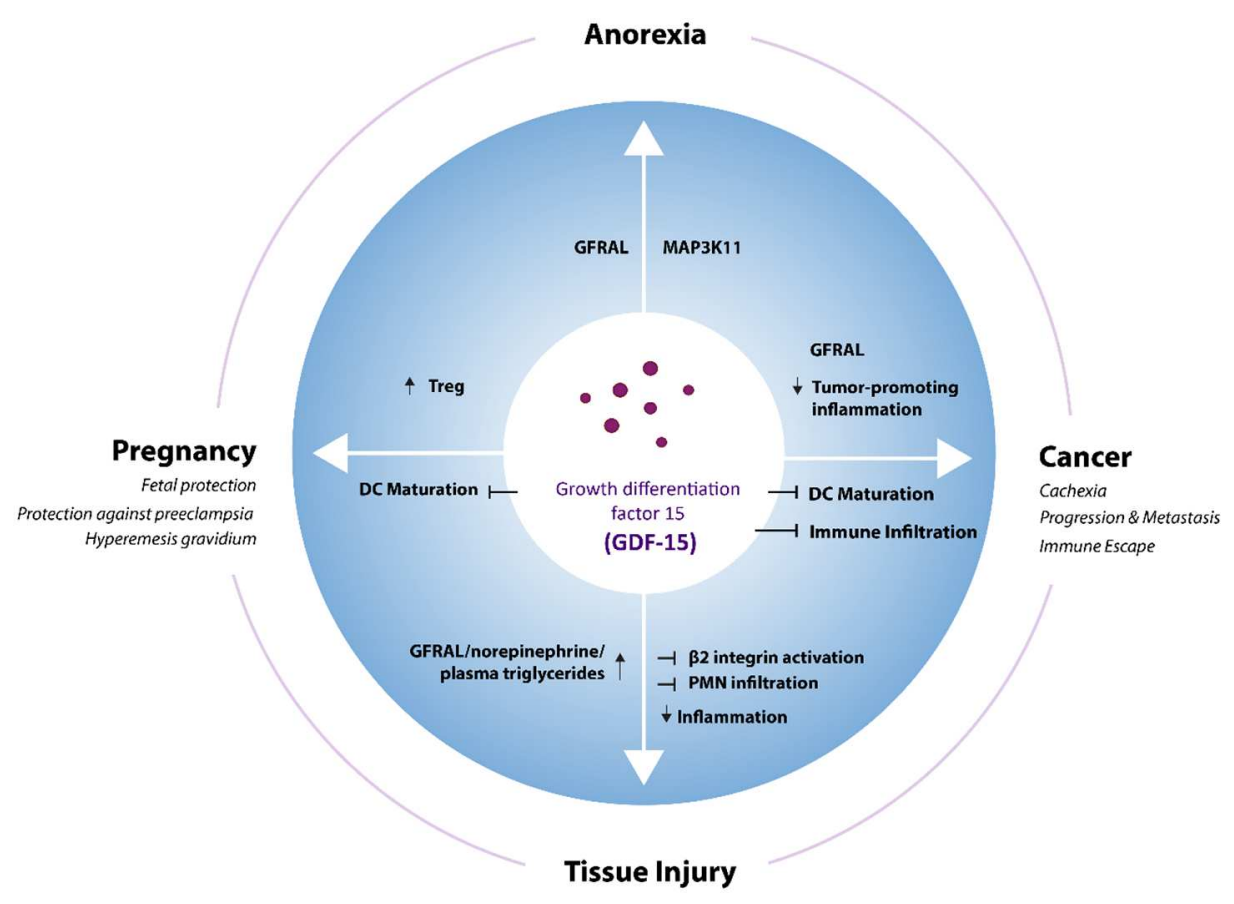

FIGURE 1 | GDF-15 in different physiological and pathological contexts. GDF-15 stimulates or inhibits different cellular processes via GFRAL and potentially other still unknown receptors in various physiological and pathophysiological situations. DC, Dendritic cells; $T_{\text {reg, }}$, regulatory T cells.

Functionally, roles in appetite regulation, metabolism, cell and tissue survival, and immune tolerance have been described. This review aims to summarize the physiological and pathophysiological functions of GDF-15 (Figure 1), with a main focus on its role in cancer and cancer immunotherapy. Certain purity issues regarding commercially distributed GDF15 reagents and their likely impact on many studies of GDF-15 mechanism of action (MOA) are also discussed. Finally, the emerging role of GDF-15 as a target for future cancer therapies is outlined.

\section{ROLE OF GDF-15 IN METABOLIC CONDITIONS}

Anorexia and cachexia are metabolic syndromes characterized by loss of appetite, progressive weight loss, reduced adipose tissue, and skeletal muscle wasting (32). This condition is mediated by yet incompletely understood secreted factors from tissues or malignant cells. More than $80 \%$ of patients with advanced stage cancer experience anorexia and cachexia. As these metabolic disorders account for $20-30 \%$ of all deaths related to cancer, they represent a significant unmet medical need (32).

Several studies have shown a direct correlation between serum GDF-15 levels and anorexia/cachexia (29, 33). Appetite is centrally regulated by the hypothalamus region of the brain (34). GDF-15 has been shown to contribute to appetite loss in xenograft mouse models of prostate cancer; and a direct correlation between increased serum GDF-15 levels and cancer-associated anorexia has been observed in prostate cancer patients (35). In a subsequent study, the neurons responsible for GDF-15 dependent induction of anorexia and cachexia were localized to the area postrema and the nucleus of the solitary tract (36). Similar observations linking GDF-15 to anorexia/cachexia were made in various other conditions such as hepatocellular carcinoma (37). Using genetically engineered xenograft mouse models, the activation of mitogen-activated protein kinase kinase kinase 11 (MAP3K11) by GDF-15 was identified as the key trigger for weight loss in animal models of cancer-related cachexia (38). Weight loss could be reverted by neutralizing antibodies against GDF-15. Modulating GDF-15 in anorexia and cachexia, where GDF-15 is the prime regulator, might thus be therapeutically beneficial (38). The role of GDF-15 in weight regulation is further supported by the observation that GDF15 transgenic mice are protected against obesity (39). GDF-15 deficient mice, in contrast, gain more weight when put on a highfat diet (40). Finally, four independent research teams from four different pharmaceutical companies (Eli Lilly, Janssen, Merck, Novo Nordisk) managed to identify GFRAL (GDNF receptor alpha-like) as the brain stem receptor mediating the metabolic effects of GDF-15 (28-30, 41). Interestingly, GDF-15 production is also induced by metformin and, at least in mice, GDF-15 is responsible for the anti-obesity effects of this most commonly prescribed type 2 diabetes drug (42). Thus, GDF-15 and GFRAL are potential drug targets in the regulation of body weight and energy expenditure.

Conversely, researchers from the Novartis Institute for Biomedical Research found that anorexia and muscle loss, as complications in cancer, are mainly caused by increased levels 
of GDF-11, with GDF-15 being upregulated in response to supraphysiologic administration of GDF-11. Blockade of GDF-11 prevented both anorexia and muscle loss, whereas inhibition of GDF-15 was most effective against anorexia (43). A recent report on pharmacological GDF-15 administration to mice, which triggered conditioned taste aversion, also links GDF-15 more closely to anorexia than to cachexia and muscle wasting (33).

\section{GDF-15 AS A MEDIATOR OF IMMUNE TOLERANCE IN NON-CANCER CONDITIONS}

GDF-15 has consistently been found to be induced in diseases involving immune homeostasis and surveillance and their regulation. Consequently, GDF-15 is implicated in physiological and pathological states where immune activation, immune surveillance and immune tolerance need to be finely balanced, because dysfunction and tissue damage are at stake.

\section{GDF-15 in Pregnancy}

The highest GDF-15 expression is found in the placenta and the fetal membrane $(11,14)$. The hypothesis that GDF-15 plays a role in feto-maternal immunotolerance was formulated in 1997 (2). Subsequent studies showed that GDF-15 serum levels are increased in pregnant women at the onset of pregnancy and reach their highest concentration at the beginning of the third trimester (44). A retrospective study on sera collected during weeks 7-13 of pregnancy found comparatively lower GDF-15 serum levels in women who subsequently experienced miscarriages $(45,46)$. Likewise, the observation that GDF-15 levels are elevated to a lesser extent in women with preeclampsia (with the more profound reduction found in late-onset cases) suggests that GDF-15 is a potential biomarker for tracking pregnancy and pregnancy-related complications (47).

The constitutive production of GDF-15 in the prostate reaching the semen may also contribute to the success of pregnancy. While GDF-15 in seminal plasma does not affect the vitality of sperm cells, GDF-15 suppresses proliferation of peripheral blood mononuclear cells (PBMCs) and induces a regulatory phenotype in $\mathrm{CD} 4{ }^{+} \mathrm{CD} 25^{+}$cells via induction of FOXP3. Thus, GDF-15 may protect sperm cells from the maternal immune system (48). Further experimental support for the ability of GDF-15 to prevent allograft rejection comes from transplantation studies, where co-injection of GDF-15overexpressing dendritic cells prolonged the average survival of C57BL/6-derived cardiac allografts in $\mathrm{BALB} / \mathrm{c}$ mice from 14 to 77.5 days, and 4/6 grafts remained fully functional for over 100 days post-transplantation. GDF-15 thus has a potent tolerogenic function and may be involved in the protection of the semiallogeneic fetus from immune-mediated rejection by the host immune system.

Interestingly, induction of anorexia and cachexia are rarely observed during pregnancy. Nevertheless, hyperemesis gravidarum (severe nausea and vomiting), which is reported in $\sim 2 \%$ of pregnant women, is linked to polymorphisms in GDF-15 or in insulin-like growth factor-binding protein (IGFBP)7 (49).
It remains to be determined whether the GDF-15 polymorphism affects the signaling function of GDF-15.

\section{GDF-15 in Metabolic Syndrome}

Due to its metabolic function, GDF-15 induces a lean phenotype in transgenic mice (50). Besides shifting the balance between obesity and leanness, GDF-15 also acts on immune cells in adipose tissue. Of particular relevance for metabolic syndrome are effects on macrophages: Lean, non-inflamed adipose tissue is inhabited by anti-inflammatory M2-like macrophages (51) which cover their metabolic demands via oxidative phosphorylation $(52,53)$. In contrast, white adipose tissue of obese individuals is infiltrated by $\mathrm{CD}^{+}$effector $\mathrm{T}$ cells. These, in turn, promote recruitment and activation of predominantly glycolytic, proinflammatory M1 macrophages (54). An excess of M1 over M2 macrophages causes metabolic changes and increased TNF- $\alpha$ levels, leading to glucose intolerance and insulin insensitivity $(55,56)$.

In response to anti-inflammatory signals, GDF-15 is locally induced in white adipose tissue macrophages $(57,58)$. Induction of metabolic syndrome in GDF-15 knock-out mice revealed that IL-4, IL-13, or rosiglitazone-based treatments depend on the JAK/STAT6- or PPAR $\gamma$-dependent upregulation of GDF15 in macrophages. In an autocrine and paracrine loop, GDF15 then activates oxidative phosphorylation in resident and recruited macrophages, thereby (re-)polarizing them toward an anti-inflammatory M2 phenotype $(52,57)$. GDF-15 deficient macrophages, in contrast, retain their M1 polarization even in the presence of anti-inflammatory cytokines. In line with its initial name macrophage inhibitory cytokine, GDF-15 thus limits pathological adipose tissue inflammation, reverts insulin resistance and ameliorates metabolic syndrome by metabolically modulating macrophage function. In humans, however, elevated GDF-15 represents a predictor for the future development of type 2 diabetes $(59,60)$ and, possibly, disease severity $(16,61)$. This still does not exclude a possible role for GDF-15 in delaying disease onset in patients at risk.

\section{GDF-15 in Tissue Injury and Inflammation}

Being an inflammatory and stress-induced cytokine, expression of GDF-15 is often increased upon tissue injury. Two studies have reported an induction of GDF-15 in response to liver injury $(62,63)$. In the earlier study, GDF-15 expression was found to be rapidly and dramatically up-regulated following various surgical and chemical treatments that cause acute liver injury and regeneration (62). The latter study reported enhanced GDF-15 levels following carbon tetrachloride $\left(\mathrm{CCl}_{4}\right)$ - or alcoholmediated liver damage (63). Functionally, hepatic GDF-15 production ameliorates liver inflammation and fibrosis. Livers of GDF-15 knockout mice showed more severe fibrosis and increased infiltration of inflammatory $\mathrm{CD} 4^{+}$and $\mathrm{CD} 8^{+} \mathrm{T}$ cells, monocytes and neutrophils.

A protective function of GDF-15 on cardiac tissue was first demonstrated by a study using GDF-15 transgenic mouse models, where GDF-15 secreted by the myocardium acted as a protective and antihypertrophic factor (64). Exploring ischemia/reperfusion injury, GDF-15-deficient mice 
developed greater infarct sizes and displayed more apoptotic cardiomyocytes in the border zone, indicating that endogenous GDF-15 limits myocardial tissue damage in vivo (65). Induction of GDF-15 after myocardial infarction was shown to be essential for limiting the recruitment of polymorphonuclear leukocytes (PMNs), thereby permitting infarct healing without causing cardiac rupture (66). By demonstrating that GDF-15 limits the recruitment of infiltrating pro-inflammatory cells by interfering with chemokine signaling and $\beta 2$-integrin/lymphocyte functionassociated antigen 1 (LFA-1) activation, this study offered the first mechanistic explanation for anti-inflammatory effects of GDF-15.

Anti-inflammatory functions of GDF-15 are also apparent in a sepsis model, in which GDF-15 knockout mice mounted increased inflammatory responses to lipopolysaccharide (LPS), with increased expression of monocyte chemoattractant protein (MCP)-1, keratinocyte chemoattractant (KC)/mouse homolog of interleukin-8 (IL-8), IL-6, and TNF- $\alpha$ in both cardiac and renal tissues, finally leading to organ dysfunction. In wild-type and GDF-15 overexpressing mice, GDF-15 protected both cardiac and renal tissues from excessive inflammation, with LPS-induced sepsis not affecting the organs (67). Induction of GDF-15 during sepsis and its tissue-protective role were very recently confirmed, where the authors described GDF15 as an "inflammation-induced central mediator of tissue tolerance" (68). Surprisingly, a GDF-15-dependent effect on tissue infiltration by pro-inflammatory immune cells in sepsis was not observed; rather, a different mechanism via activation of GFRAL inducing $\beta$-adrenergic signaling to stimulate the release of triglycerides from the liver was proposed. Cardio-protection is then achieved by maintaining triglyceride levels during acute inflammation. GDF-15 thus appears to promote metabolic adaptation to systemic inflammation (68). Interestingly, an earlier study from the same group has shown that switching to a fasting metabolism (which should be a consequence of GDF-15/GFRAL/RET-induced anorexia) can be life-saving in LPS- or Listeria-induced experimental sepsis (69).

By proposing that the central metabolic effects of GDF-15 are crucial for limiting inflammation-induced tissue damage, Luan et al. suggest an elegant link between the known functions of GDF-15 (68). Still, direct effects of GDF-15 on immune cells, as observed in previous studies $(63,66)$, would contribute toward a similar functional outcome. Irrespective of the underlying mechanism, there is consensus that GDF15 protects the heart, liver and kidney after injury or stress, and regulates injury-mediated response in the lungs (70-72). Finally, an immunohistochemical analysis of benign atrophic lesions of the human prostate (where GDF-15 is constitutively expressed) revealed an inverse correlation between GDF-15 and infiltration by $\mathrm{CD}^{+}, \mathrm{CD}^{+}, \mathrm{CD}^{+}, \mathrm{CD}^{+} 8^{+}$, and $\mathrm{iNOS}^{+}$ leukocytes, whereas no correlation was observed with infiltration of arginase-positive (most likely myeloid-derived suppressor) cells (73). Thus, there is ample evidence that GDF-15 can limit inflammation-induced damage and help to preserve tissue integrity.

\section{Autoimmune Diseases}

Autoimmune diseases result from often chronic aberrant immune responses against self-antigens with immune cells turning against host tissues. One of the most common autoimmune diseases is rheumatoid arthritis. Patients suffering from rheumatoid arthritis often display elevated GDF-15 levels, which correlate with symptoms such as erythrocyte sedimentation rate levels, morning stiffness, tender joint count, and carotid intima media thickness (74). For another autoimmune disease, Type 1 diabetes (T1D), elevated GDF15 activity was described in beta cells (75), and GDF-15 was proposed as a biomarker for T1D (16). Functionally, GDF-15 was shown to protect pancreatic $\beta$-cells under inflammatory conditions and in non-obese diabetic mice. A possible protective effect against T1D was further corroborated by a reduced abundance of GDF-15 in post mortem islets from individuals with T1D (76). While these observations can be explained by the induction of GDF-15 under inflammatory conditions, a completely different outcome is observed in multiple sclerosis. In a well-characterized, longitudinally followed cohort of 48 patients with multiple sclerosis, GDF-15 was only elevated in a small subset of patients who were characterized by a stable course of disease with no relapse or further gadolinium-enhancing lesions over an average observational period of 5.9 years (77). Thus, in multiple sclerosis GDF-15 seems to be a biomarker for a stable course of disease rather than severity. A possible causal or functional relationship remains to be investigated.

Thus, GDF-15 seems to have a broad and diverse functional role in various conditions. Apart from its effects on appetite and body weight regulation, it protects the fetus by inhibiting $\mathrm{T}$ cells, protects other tissues against excessive inflammation, and is induced in many pathologies where GDF-15 function appears to be context-dependent.

\section{GDF-15 IN CANCER}

\section{GDF-15 as a Prognostic and Predictive Marker in Numerous (Solid) Cancer Entities}

In a large-scale screening, GDF-15 was the most prominently overexpressed soluble factor across a large range of cancer types (20). GDF-15 was further proposed as a diagnostic biomarker in, e.g., colorectal $(78,79)$, ovarian $(80)$, and early-stage lung cancer $(79,81)$. In fact, GDF-15 was found to be the most accurate marker at differentiating pancreatic adenocarcinoma from chronic pancreatitis (82). As an essential component of more complex marker panels, GDF-15 is a potential marker to aid in the discrimination between prostate cancer and benign hyperplasia (83-85). Correlations between GDF-15 and cancer progression have been described for colorectal $(86,87)$, gastric (88-91), hepatocellular carcinoma (92), non-small cell lung cancer (81), urothelial/renal cell (93), ovarian (80), melanoma (94), breast (20, 95), multiple myeloma (96, 97), and oral cancers (98). Findings from these studies indicate that GDF15 is a promising prognostic marker for identifying cancer manifestation and progression. 
GDF-15 is, however, more than a surrogate marker for tumor progression and tumor load. GDF-15 also remains highly predictive regarding clinical outcome in multi-variate analyses with other markers reflecting tumor burden $(80,81,90,94,99)$. In colorectal cancer, a meta-analysis built upon eight individual studies concluded that higher GDF-15 expression is associated with worse overall survival, with a pooled hazard ratio (HR) of 2.09 [95\% confidence interval (CI): 1.47-2.96] (78). In prostate cancer, GDF-15 serum levels independently predicted lower cancer-specific survival with an adjusted HR of 2.98 (95\% CI: 1.82-4.68). Patients with high pretreatment GDF-15 levels even showed an 8-fold higher death rate than those with low GDF-15 (adjusted HR: 7.98; 95\% CI: 1.73-36.86). Strikingly, a sequence variant in the GDF-15 gene that was associated with decreased GDF-15 serum levels $(P=0.002)$ was also associated with decreased mortality $(P=0.003)$, suggesting a disease-modifying influence of GDF-15 (100).

In patients with stage I and II non-small cell lung cancer, multivariate Cox regression survival analysis showed that high GDF-15 in serum was an independent risk factor for reduced overall survival $(\mathrm{HR}=3.37,95 \% \mathrm{CI}: 1.09-10.42, p=0.035)$ (81). In patients with tumor-free stage III or unresectable stage IV melanoma, there was such a significant link between elevated GDF-15 serum levels and poor survival that the clinically wellestablished marker LDH was no longer statistically significant in the multivariate analyses (94). In uveal melanoma, elevated GDF-15 correlated with the presence of metastases $(p<0.001)$ (101). In ovarian cancer, elevated GDF-15 was identified as an independent predictor for poor progression-free and overall survival, even after correction for FIGO stage and age $(p=0.01)$ $(102,103)$. GDF-15 was further reported to predict the failure of platinum-based chemotherapy and proposed as a diagnostic biomarker in ovarian cancer (80). In endometrial cancer, high plasma GDF-15 was, again, an independent predictor of poor disease-specific and short recurrence-free survival and was significantly associated with high tumor grade and lymph node metastasis (all $p \leq 0.001$ ) (104).

In esophageal cancer, elevated GDF-15 was positively associated with tumor invasion $(p=0.030)$, lymph node metastasis $(P=0.007)$, and shorter relapse-free $(p=0.050)$ and tumor-specific survival $(p=0.005)$. Moreover, GDF-15 was the strongest predictor for outcome compared with other markers tested in the same patient cohort (105). Among patients with oral squamous cell carcinoma, those with elevated GDF-15 showed significantly shorter survival $(p=0.031)(98)$. In gastric cancer, increased levels of GDF-15 were associated with reduced progression-free and overall survival in univariate analyses; in multivariate analyses, high GDF-15 in combination with MMP7 and miR-200c was an independent predictor for death $(p=$ 0.033 ) (90). In glioma, increased GDF-15 in cerebrospinal fluid correlated strongly with shorter survival $(p=0.007)(106)$. The association between high GDF-15 expression and poor survival of glioma patients was further confirmed following TCGA database interrogation ( $p=0.017$ ) (107). Similarly, in pancreatic cancer, an analysis based on 108 gene expression profiles from the TCGA database found a correlation between high GDF-15 expression and poor survival; however (possibly due to the generally dismal prognosis), this finding was not statistically significant ( $p=$ $0.105)$ (108).

In multiple myeloma where GDF-15 is produced by bone marrow stromal cells rather than by the tumor, increased GDF-15 serum levels were associated with a tumor-promoting microenvironment, as demonstrated by enhanced clonogenic growth of multiple myeloma cells and reduced progression-free survival (96). Apart from this study there is little evidence for the involvement of GDF-15 in hematological malignancies. In solid cancers, however, the epidemiological evidence for a correlation between elevated GDF-15 on protein level and poor survival is almost overwhelming (Table 1).

A disease-modifying effect of GDF-15 is further supported by findings that a polymorphism in the GDF15 gene (H6D) affects both tumor risk and prognosis in colorectal $(113,128)$ and in prostate cancer (HR: 0.83 or 0.85 from two different studies) $(129,130)$. Interestingly, the H6D genotype is associated with lower tumor risk and correlates with more aggressive growth and an increased risk of death (HR: 1.72; 95\% CI: 1.06-2.78; $p=0.03$ ), once prostate cancer has developed (130).

As a potential biomarker for immunotherapy, GDF-15 was included in a study exploring possible predictors for resistance to anti-CTLA-4 (Ipilimumab) therapy. In this analysis, GDF-15, endostatin, osteoprotegerin, C-reactive protein, pulmonary and activation-regulated chemokine and galectin-3 binding-protein that were persistently higher in non-survivors. Statistically, however, effects were significant only prior to multivariable adjustment ( $p=0.01$ for GDF-15) (118). However, as this study was only based on serum samples from only 56 melanoma patients, a possible correlation remains to be further explored in a larger cohort.

\section{GDF-15 in Cancer-Induced Anorexia/Cachexia}

A prevalent and often fatal complication in patients affected with cancer is anorexia and cachexia syndrome (32). Based on the initial observation that tumor-derived GDF-15 induces this condition (35), on the localization of the underlying signaling mechanism to the brainstem (131), and on the identification of the brainstem-restricted GDF-15 receptor GFRAL and its signaling pathway via RET (28-30, 41), GDF-15 and GFRAL have become major targets for appetite and weight regulation. The subsequent finding that GDF-15 is primarily responsible for the loss of appetite, whereas loss of muscle mass depends more on GDF-11 (43), may, however, limit the usefulness of anti-GDF-15 (mono)therapy in cancer patients with muscle wasting syndrome.

\section{GDF-15 in Tumor Immune Evasion}

The ability of tumor cells to evade immune surveillance (132, 133 ) is now considered a hallmark of cancer (134). The immunological contexture within the tumor microenvironment has also been recognized as a major predictor for survival $(135,136)$. This immune effect is reflected in the tremendous predictive power of Immunoscore $(137,138)$ which defines the immune "fitness" of a given tumor host interaction-based on the localization of CD8 T lymphocytes in the invasive front and the 
TABLE 1 | Correlation between GDF-15 serum and/or tumor levels with clinical outcome in different cancer types.

\begin{tabular}{|c|c|c|c|c|c|c|c|c|}
\hline Indication & Patient cohort & Patient numbers & $\begin{array}{l}\text { GDF-15 plasma/ } \\
\text { serum assay }\end{array}$ & Assay matrix & $\begin{array}{l}\text { Plasma/Serum } \\
\text { threshold }\end{array}$ & $\begin{array}{l}\text { GDF-15 expression } \\
\text { tumor (IHC or RNA) }\end{array}$ & $\begin{array}{l}\text { Correlation with clinical } \\
\text { outcome and disease } \\
\text { markers }\end{array}$ & References \\
\hline Breast cancer (BC) & $\begin{array}{l}\text { Gustave Roussy Cancer } \\
\text { Center, Villejuif, France }\end{array}$ & $605 \mathrm{BC}$ patients & Not applicable & Not applicable & Not determined & $\begin{array}{l}\text { GDF-15 IHC of } 605 \mathrm{BC} \\
\text { patients }\end{array}$ & $\begin{array}{l}\text { Tumor GDF-15 expression } \\
\text { correlates with ER-negative and } \\
\text { HER2-positive status in patients } \\
\text { with breast cancer }\end{array}$ & (109) \\
\hline \multirow[t]{7}{*}{$\begin{array}{l}\text { Colorectal cancer } \\
\text { (CRC) }\end{array}$} & $\begin{array}{l}\text { Nurses' Health Study (NHS), } \\
\text { Health Professionals } \\
\text { Follow-up Study (HPFS), } \\
\text { USA }\end{array}$ & $\begin{array}{l}616 \text { CRC patients from } \\
2 \text { independent patient } \\
\text { cohorts }\end{array}$ & $\begin{array}{l}\text { GDF-15 ELISA (R\&D } \\
\text { Systems) }\end{array}$ & Plasma & $1,060 \mathrm{pg} / \mathrm{mL}$ & Not applicable & $\begin{array}{l}\text { Plasma GDF-15 above threshold } \\
\text { correlates with shorter OS }\end{array}$ & (87) \\
\hline & $\begin{array}{l}\text { Zhejiang University Sir Run } \\
\text { Run Shaw Hospital, China }\end{array}$ & 138 CRC patients & $\begin{array}{l}\text { GDF-15 ELISA (not } \\
\text { defined) }\end{array}$ & Serum & $1,150 \mathrm{pg} / \mathrm{mL}$ & Not applicable & $\begin{array}{l}\text { Serum GDF- } 15 \text { above threshold } \\
\text { correlates with shorter OS }\end{array}$ & (110) \\
\hline & $\begin{array}{l}\text { Charles University and } \\
\text { General University Hospital, } \\
\text { Czech Republic }\end{array}$ & $\begin{array}{l}97 \text { metastatic CRC } \\
\text { patients }\end{array}$ & $\begin{array}{l}\text { GDF-15 ELISA } \\
\text { (Biovendor-Laboratorni } \\
\text { medicina) }\end{array}$ & Serum & $7,000 \mathrm{pg} / \mathrm{mL}$ & Not applicable & $\begin{array}{l}\text { Serum levels of GDF-15 were } \\
\text { significantly higher in patients } \\
\text { with colorectal cancer compared } \\
\text { to healthy controls. GDF-15 } \\
\text { correlates with shorter OS. }\end{array}$ & (111) \\
\hline & $\begin{array}{l}\text { Nurses' Health Study (NHS), } \\
\text { USA }\end{array}$ & 757 CRC patients & $\begin{array}{l}\text { GDF-15 ELISA (R\&D } \\
\text { Systems) }\end{array}$ & Plasma & Not determined & Not applicable & $\begin{array}{l}\text { Elevated levels of plasma } \\
\text { GDF- } 15 \text { were associated with } \\
\text { higher risk of advanced } \\
\text { colorectal cancer }\end{array}$ & (112) \\
\hline & $\begin{array}{l}\text { The Johns Hopkins } \\
\text { Hospital, USA St. Vincent's } \\
\text { Hospital, Australia }\end{array}$ & $\begin{array}{l}525 \text { CRC patients from } \\
2 \text { independent patient } \\
\text { cohorts }\end{array}$ & $\begin{array}{l}\text { GDF-15 ELISA } \\
\text { (in-house) }\end{array}$ & Serum & $1,150 \mathrm{pg} / \mathrm{mL}$ & Not applicable & $\begin{array}{l}\text { Serum levels of GDF-15 were } \\
\text { significantly higher in patients } \\
\text { with colorectal cancer compared } \\
\text { to healthy controls. Serum } \\
\text { GDF-15 above threshold } \\
\text { correlates with disease } \\
\text { progression and shorter OS }\end{array}$ & (113) \\
\hline & Vasteras Hospital, Sweden & 320 CRC patients & GDF-15 SP-PLA & $\begin{array}{l}\text { Plasma (60 } \\
\text { patients) }\end{array}$ & $1,150 \mathrm{pg} / \mathrm{mL}$ & $\begin{array}{l}\text { GDF- } 15 \text { IHC of } 274 \\
\text { CRC patients }\end{array}$ & $\begin{array}{l}\text { Moderate or high tumor GDF-15 } \\
\text { intensity correlates an increased } \\
\text { risk of recurrence and with } \\
\text { shorter OS }\end{array}$ & (114) \\
\hline & $\begin{array}{l}\text { Chinese Academy of } \\
\text { Medical Sciences } \\
\text { (CICAMS), }\end{array}$ & 473 CRC patients & $\begin{array}{l}\text { GDF-15 ELISA } \\
\text { (in-house) }\end{array}$ & Serum & $1,000 \mathrm{pg} / \mathrm{mL}$ & Not applicable & $\begin{array}{l}\text { Serum GDF-15 is significantly } \\
\text { higher in patients with stage IV } \\
\text { CRC compared to stage I-III and } \\
\text { healthy individuals. Patients with } \\
\text { liver metastasis have elevated } \\
\text { serum levels of GDF-15. Disease } \\
\text { recurrence is associated with } \\
\text { increase of serum GDF-15 levels. } \\
\text { Patients with higher serum } \\
\text { GDF-15 had a trend to poorer } \\
\text { tumor-specific survival }\end{array}$ & (79) \\
\hline
\end{tabular}


TABLE 1 | Continued

\begin{tabular}{|c|c|c|c|c|c|c|c|c|}
\hline Indication & Patient cohort & Patient numbers & $\begin{array}{l}\text { GDF-15 plasma/ } \\
\text { serum assay }\end{array}$ & Assay matrix & $\begin{array}{l}\text { Plasma/Serum } \\
\text { threshold }\end{array}$ & $\begin{array}{l}\text { GDF-15 expression } \\
\text { tumor (IHC or RNA) }\end{array}$ & $\begin{array}{l}\text { Correlation with clinical } \\
\text { outcome and disease } \\
\text { markers }\end{array}$ & References \\
\hline \multirow[t]{2}{*}{$\begin{array}{l}\text { Endometrial } \\
\text { Cancer }\end{array}$} & $\begin{array}{l}\text { Oslo University Hospital \& } \\
\text { Haukeland University } \\
\text { Hospital, Norway }\end{array}$ & $\begin{array}{l}510 \text { endometrial cancer } \\
\text { patients }\end{array}$ & $\begin{array}{l}\text { Immunoradiometric } \\
\text { sandwich assay using a } \\
\text { polyclonal, affinity } \\
\text { chromatography- } \\
\text { purified goat } \\
\text { anti-human GDF-15 } \\
\text { IgG antibody (R\&D } \\
\text { Systems) }\end{array}$ & Plasma & $\begin{array}{l}\text { Upper tertile of } \\
\text { GDF-15 level } \\
\text { (median }=1,077 \\
\text { pg(mL) }\end{array}$ & Not applicable & $\begin{array}{l}\text { High plasma GDF-15 is } \\
\text { associated with metastatic } \\
\text { disease. GDF-15 above } \\
\text { threshold correlates with shorter } \\
\text { PFS and OS }\end{array}$ & (104) \\
\hline & $\begin{array}{l}\text { Haukeland University } \\
\text { Hospital, Norway }\end{array}$ & $\begin{array}{l}235 \text { endometrial cancer } \\
\text { patients }\end{array}$ & $\begin{array}{l}\text { GDF-15 ELISA (R\&D } \\
\text { Systems) }\end{array}$ & Plasma & $\begin{array}{l}\text { Upper tertile of } \\
\text { GDF-15 level } \\
\text { (median }=1,780 \\
\mathrm{pg} / \mathrm{mL} \text { (range } \\
518-9,475 \mathrm{pg} / \mathrm{mL} \text { ) }\end{array}$ & Not applicable & $\begin{array}{l}\text { High plasma level GDF-15 } \\
\text { independently predicts recurrent } \\
\text { disease and lymph node } \\
\text { metastases. GDF-15 above } \\
\text { threshold correlates with shorter } \\
\text { PFS and OS }\end{array}$ & (115) \\
\hline $\begin{array}{l}\text { Esophageal } \\
\text { cancer }\end{array}$ & $\begin{array}{l}\text { Chinese Academy of } \\
\text { Medical Sciences } \\
\text { (CICAMS), China }\end{array}$ & 286 ESCC patients & $\begin{array}{l}\text { GDF-15 ELISA } \\
\text { (in-house) }\end{array}$ & Serum & $1,000 \mathrm{pg} / \mathrm{mL}$ & $\begin{array}{l}\text { GDF- } 15 \mathrm{IHC} \text { of } 40 \\
\text { Patients }\end{array}$ & $\begin{array}{l}\text { Serum GDF15 decreased after } \\
\text { surgical removal and increased } \\
\text { at relapse. GDF-15 above } \\
\text { threshold correlates with shorter } \\
\text { relapse-free survival and } \\
\text { tumor-specific survival }\end{array}$ & (105) \\
\hline Gastric cancer & $\begin{array}{l}\text { Dankook University College } \\
\text { of Medicine, Korea }\end{array}$ & $\begin{array}{l}80 \text { gastric cancer } \\
\text { patients }\end{array}$ & $\begin{array}{l}\text { GDF-15 ELISA (R\&D } \\
\text { Systems) }\end{array}$ & $\begin{array}{l}\text { Serum (80 } \\
\text { patients) }\end{array}$ & Not determined & 41 patients & $\begin{array}{l}\text { Serum GDF-15 and tumor } \\
\text { GDF-15 (protein and mRNA) } \\
\text { expression is higher in patients } \\
\text { with gastric cancer. Tumor } \\
\text { GDF15 correlates with } \\
\text { differentiation stage }\end{array}$ & (89) \\
\hline \multirow[t]{2}{*}{ Gastric cancer } & $\begin{array}{l}\text { Peking University Cancer } \\
\text { Hospital, China }\end{array}$ & $\begin{array}{l}384 \text { gastric cancer } \\
\text { patients }\end{array}$ & $\begin{array}{l}\text { GDF-15 ELISA } \\
\text { (in-house) }\end{array}$ & $\begin{array}{l}\text { Serum ( } 217 \\
\text { patients) }\end{array}$ & $1,120 \mathrm{pg} / \mathrm{mL}$ & Not applicable & $\begin{array}{l}\text { Serum GDF- } 15 \text { levels above } \\
\text { threshold before chemotherapy } \\
\text { and increased GDF-15 levels } \\
\text { during chemotherapy correlate } \\
\text { with shorter OS }\end{array}$ & (116) \\
\hline & $\begin{array}{l}\text { La Coruña Biomedical } \\
\text { Research Institute (INIBIC), } \\
\text { Spain }\end{array}$ & $\begin{array}{l}52 \text { gastric cancer } \\
\text { patients }\end{array}$ & $\begin{array}{l}\text { GDF-15 ELISA (R\&D } \\
\text { Systems) }\end{array}$ & Serum & $493 \mathrm{pg} / \mathrm{mL}$ & Not applicable & $\begin{array}{l}\text { Serum GDF-15 above threshold } \\
\text { correlates with shorter PFS and } \\
\text { OS }\end{array}$ & (90) \\
\hline \multirow[t]{2}{*}{ Glioblastoma } & $\begin{array}{l}\text { Center Hospitalier } \\
\text { Universitaire Vaudois, } \\
\text { Lausanne, Switzerland }\end{array}$ & $\begin{array}{l}33 \text { patients with } \\
\text { glioblastoma }\end{array}$ & $\begin{array}{l}\text { GDF-15 ELISA } \\
\text { (in-house) }\end{array}$ & $\begin{array}{l}\text { Plasma } \\
\text { Cerebrospinal fluid } \\
\text { (CSF) }\end{array}$ & $156 \mathrm{pg} / \mathrm{mL}$ & Not applicable & $\begin{array}{l}\text { GDF-15 (CSF) above threshold } \\
\text { correlates with shorter OS }\end{array}$ & (106) \\
\hline & $\begin{array}{l}\text { TCGA database (http:// } \\
\text { cancergenome.nih.gov), }\end{array}$ & $\begin{array}{l}540 \text { glioblastoma } \\
\text { patients (TCGA) }\end{array}$ & Not applicable & Not applicable & Not determined & $\begin{array}{l}\text { GDF-15 tumor mRNA } \\
\text { expression obtained } \\
\text { from TCGA }\end{array}$ & $\begin{array}{l}\text { Low GDF- } 15 \text { tumor mRNA } \\
\text { expression correlate with better } \\
\text { outcome in glioblastoma }\end{array}$ & (107) \\
\hline
\end{tabular}




\begin{tabular}{|c|c|c|c|c|c|c|c|c|}
\hline Indication & Patient cohort & Patient numbers & $\begin{array}{l}\text { GDF-15 plasma/ } \\
\text { serum assay }\end{array}$ & Assay matrix & $\begin{array}{l}\text { Plasma/Serum } \\
\text { threshold }\end{array}$ & $\begin{array}{l}\text { GDF-15 expression } \\
\text { tumor (IHC or RNA) }\end{array}$ & $\begin{array}{l}\text { Correlation with clinical } \\
\text { outcome and disease } \\
\text { markers }\end{array}$ & References \\
\hline \multirow[t]{3}{*}{$\begin{array}{l}\text { Head and neck } \\
\text { cancer (HNSCC) }\end{array}$} & $\begin{array}{l}\text { Johannes } \\
\text { Gutenberg-University Mainz, } \\
\text { Germany }\end{array}$ & 64 OSCC patients & $\begin{array}{l}\text { GDF-15 ELISA (R\&D } \\
\text { Systems) }\end{array}$ & Serum & $875 \mathrm{pg} / \mathrm{ml}$ & Not applicable & $\begin{array}{l}\text { Serum GDF-15 above threshold } \\
\text { correlates with shorter OS and } \\
\text { tumor load }\end{array}$ & (98) \\
\hline & $\begin{array}{l}\text { Ninth People's Hospital, } \\
\text { Shanghai Jiao Tong } \\
\text { University School of } \\
\text { Medicine, China }\end{array}$ & $\begin{array}{l}256 \text { stage III and IV } \\
\text { OSCC patients }\end{array}$ & Not applicable & Not applicable & Not determined & $\begin{array}{l}\text { GDF-15 IHC of } 256 \\
\text { patients }\end{array}$ & $\begin{array}{l}\text { Elevated tumor tissue expression } \\
\text { of GDF-15 correlates with shorter } \\
\text { PFS and OS. Docetaxel, cisplatin } \\
\text { and 5-fluorouracil (TPF) induction } \\
\text { chemotherapy is beneficial for } \\
\text { patients with elevated tumor } \\
\text { GDF-15 expression }\end{array}$ & \\
\hline & $\begin{array}{l}\text { Ninth People's Hospital, } \\
\text { Shanghai Jiao Tong } \\
\text { University School of } \\
\text { Medicine, China }\end{array}$ & 60 OSCC patients & $\begin{array}{l}\text { GDF-15 ELISA (R\&D } \\
\text { Systems) }\end{array}$ & Serum & $364 \mathrm{pg} / \mathrm{mL}$ & Not applicable & $\begin{array}{l}\text { GDF-15 above threshold did not } \\
\text { significantly correlate with shorter } \\
\text { OS }\end{array}$ & (117) \\
\hline Melanoma & $\begin{array}{l}\text { University Hospital } \\
\text { Tubingen, Germany }\end{array}$ & $\begin{array}{l}761 \text { stage III/IV } \\
\text { melanoma patients }\end{array}$ & $\begin{array}{l}\text { GDF-15 ELISA (R\&D } \\
\text { Systems) }\end{array}$ & Serum & $1,500 \mathrm{pg} / \mathrm{mL}$ & Not applicable & $\begin{array}{l}\text { Elevated GDF-15 correlates with } \\
\text { shorter OAS }\end{array}$ & (94) \\
\hline \multirow[t]{3}{*}{ Melanoma } & $\begin{array}{l}\text { Oslo University Hospital The } \\
\text { Norwegian Radium } \\
\text { Hospital, Norway }\end{array}$ & $\begin{array}{l}69 \text { patients with } \\
\text { unresectable or } \\
\text { metastatic malignant } \\
\text { melanoma were treated } \\
\text { with ipilimumab (Phase } \\
\text { IV study } \\
\text { (NCT0268196/EudraCT20 } \\
\text { 002408-15) }\end{array}$ & $\begin{array}{l}\text { GDF-15 ELISA (R\&D } \\
\text { Systems) } \\
\text { 013- }\end{array}$ & $\begin{array}{l}\text { Serum (56 } \\
\text { patients) }\end{array}$ & $517 \mathrm{pg} / \mathrm{mL}$ & Not applicable & $\begin{array}{l}\text { In univariable analysis baseline } \\
\text { GDF-15 above threshold } \\
\text { correlated with shorter survival. } \\
\text { The association between survival } \\
\text { and GDF-15 was markedly } \\
\text { attenuated by multivariable } \\
\text { adjustment and was no longer } \\
\text { significantly associated with } \\
\text { death under subsequent } \\
\text { ipilimumab treatment }\end{array}$ & (118) \\
\hline & $\begin{array}{l}\text { Pennsylvania State } \\
\text { University, USA }\end{array}$ & 29 melanoma patients & $\begin{array}{l}\text { GDF-15 ELISA (R\&D } \\
\text { Systems) }\end{array}$ & $\begin{array}{l}\text { Serum (10 } \\
\text { patients) }\end{array}$ & Not determined & 22 patients & $\begin{array}{l}\text { Primary melanoma biopsies } \\
\text { expressing low levels of GDF- } 15 . \\
\text { Metastatic melanoma patients } \\
\text { having elevated GDF-15 } \\
\text { expression in tumors also had } \\
\text { high levels of GDF-15 in serum }\end{array}$ & (119) \\
\hline & $\begin{array}{l}\text { Queensland Institute of } \\
\text { Medical Research and } \\
\text { Princess Alexandra Hospital }\end{array}$ & $\begin{array}{l}22 \text { primary melanoma } \\
\text { and } 16 \text { metastatic } \\
\text { melanoma patients }\end{array}$ & Not applicable & Not applicable & Not determined & 38 patients & $\begin{array}{l}\text { Elevated GDF-15 tissue } \\
\text { expression, detected by IHC, } \\
\text { was significantly associated with } \\
\text { metastatic melanoma and not } \\
\text { primary melanoma }\end{array}$ & (120) \\
\hline $\begin{array}{l}\text { Hepato-cellular } \\
\text { Carcinoma (HCC) }\end{array}$ & $\begin{array}{l}\text { Chinese Academy of } \\
\text { Medical Sciences } \\
\text { (CICAMS), China }\end{array}$ & $223 \mathrm{HCC}$ patients & $\begin{array}{l}\text { GDF-15 ELISA (R\&D } \\
\text { Systems) }\end{array}$ & Serum & $2.463 \mathrm{ng} / \mathrm{mL}$ & $\begin{array}{l}\text { GDF- } 15 \mathrm{IHC} \text { of } 20 \\
\text { HCC patients }\end{array}$ & $\begin{array}{l}\text { Tumor GDF15 protein expression } \\
\text { in HCC was significantly higher } \\
\text { than that in the corresponding } \\
\text { adjacent paracarcinomatous } \\
\text { tissue and normal liver. Serum } \\
\text { GDF15 level is elevated in } \\
\text { patients with HCC }\end{array}$ & (92) \\
\hline
\end{tabular}


TABLE 1 | Continued

\begin{tabular}{|c|c|c|c|c|c|c|c|c|}
\hline Indication & Patient cohort & Patient numbers & $\begin{array}{l}\text { GDF-15 plasma/ } \\
\text { serum assay }\end{array}$ & Assay matrix & $\begin{array}{l}\text { Plasma/Serum } \\
\text { threshold }\end{array}$ & $\begin{array}{l}\text { GDF-15 expression } \\
\text { tumor (IHC or RNA) }\end{array}$ & $\begin{array}{l}\text { Correlation with clinical } \\
\text { outcome and disease } \\
\text { markers }\end{array}$ & References \\
\hline \multirow[t]{3}{*}{ Multiple myeloma } & $\begin{array}{l}\text { Franccophone du Myelome } \\
\text { treatment trials, France }\end{array}$ & $\begin{array}{l}131 \text { multiple myeloma } \\
\text { patients }\end{array}$ & $\begin{array}{l}\text { GDF-15 ELISA (R\&D } \\
\text { Systems) }\end{array}$ & Plasma & $500 \mathrm{pg} / \mathrm{mL}$ & & $\begin{array}{l}\text { GDF-15 correlates with shorter } \\
\text { event-free survival and OS and } \\
\beta 2 \text {-microglobulin level and } \\
\text { disease stage }\end{array}$ & (121) \\
\hline & $\begin{array}{l}\text { University Hospital Malmo, } \\
\text { Sweden }\end{array}$ & $\begin{array}{l}138 \text { multiple myeloma } \\
\text { patients }\end{array}$ & $\begin{array}{l}\text { GDF-15 MILLIPLEX } \\
\text { MAP Human Panel } \\
\text { (Millipore) }\end{array}$ & Serum & $1,008 \mathrm{pg} / \mathrm{mL}$ & & $\begin{array}{l}\text { GDF-15 above threshold } \\
\text { correlates with shorter OS }\end{array}$ & (97) \\
\hline & $\begin{array}{l}\text { The Johns Hopkins } \\
\text { Hospital, USA }\end{array}$ & $\begin{array}{l}15 \text { multiple myeloma } \\
\text { patients }\end{array}$ & $\begin{array}{l}\text { GDF-15 ELISA (R\&D } \\
\text { Systems) }\end{array}$ & Serum & Not determined & Not applicable & $\begin{array}{l}\text { Increased serum GDF-15 levels } \\
\text { correlate with shorter OS }\end{array}$ & (96) \\
\hline \multirow[t]{2}{*}{$\begin{array}{l}\text { Non-small cell lung } \\
\text { cancer (NSCLC) }\end{array}$} & $\begin{array}{l}\text { Nanjing Medical University } \\
\text { Jiangsu, China }\end{array}$ & $\begin{array}{l}46 \text { stage I/II and } 20 \\
\text { stage III/IV NSCLC } \\
\text { patients }\end{array}$ & Not applicable & Not determined & Not determined & $\begin{array}{l}\text { GDF15 mRNA by } \\
\text { qRT-PCR of } 66 \text { NSCLC } \\
\text { patients }\end{array}$ & $\begin{array}{l}\text { Downregulated GDF15 mRNA in } \\
\text { NSCLC tissues is correlated with } \\
\text { poor clinical outcomes in NSCLC }\end{array}$ & (122) \\
\hline & $\begin{array}{l}\text { Cancer Institute and } \\
\text { Hospital Beijing, China }\end{array}$ & $\begin{array}{l}152 \text { stage I and II } \\
\text { NCSCL patients }\end{array}$ & $\begin{array}{l}\text { GDF-15 ELISA } \\
\text { (in-house) }\end{array}$ & Serum & $1,465 \mathrm{pg} / \mathrm{mL}$ & & $\begin{array}{l}\text { Serum GDF-15 above threshold } \\
\text { correlates with shorter OS }\end{array}$ & (81) \\
\hline $\begin{array}{l}\text { Esophageal } \\
\text { adeno-carcinoma } \\
\text { (OAC) }\end{array}$ & $\begin{array}{l}\text { St. Vincent's Hospital, } \\
\text { Australia \& PROBE-NET } \\
\text { study, Australia }\end{array}$ & 138 OAC patients & $\begin{array}{l}\text { GDF-15 ELISA } \\
\text { (in-house) }\end{array}$ & Plasma & $1,140 \mathrm{pg} / \mathrm{mL}$ & $\begin{array}{l}\text { GDF } 15 \text { mRNA by } \\
\text { MT-PCR of } 138 \text { OAC } \\
\text { patients }\end{array}$ & $\begin{array}{l}\text { GDF15 mRNA tissue expression } \\
\text { is higher in esophageal } \\
\text { adenocarcinoma compared to } \\
\text { healthy individuals. Plasma } \\
\text { GDF-15 above threshold } \\
\text { correlates with shorter OS in } \\
\text { OAC }\end{array}$ & (123) \\
\hline Pancreatic cancer & $\begin{array}{l}\text { Arthur G. James } \\
\text { Comprehensive Cancer } \\
\text { Center, USA }\end{array}$ & $\begin{array}{l}27 \text { PDAC patients, } 183 \\
\text { PDAC patients from the } \\
\text { TCGA database. }\end{array}$ & $\begin{array}{l}\text { GDF-15 ELISA (R\&D } \\
\text { Systems) }\end{array}$ & Serum & Not determined & Not applicable & $\begin{array}{l}\text { GDF15 mRNA expression shows } \\
\text { trend for shorter OS }\end{array}$ & (108) \\
\hline \multirow[t]{3}{*}{ Ovarian cancer } & Xijing Hospital, China, & 145 EOC patients & $\begin{array}{l}\text { GDF-15 ELISA } \\
\text { (USCNLIFE) }\end{array}$ & $\begin{array}{l}\text { Serum (120 } \\
\text { patients) }\end{array}$ & $748 \mathrm{pg} / \mathrm{mL}$ & 145 patients & $\begin{array}{l}\text { High GDF-15 expression in EOC } \\
\text { tissue showed shorter PFS and } \\
\text { OS. Serum GDF-15 levels where } \\
\text { higher in EOC patients resistant } \\
\text { to first-line chemotherapy }\end{array}$ & (103) \\
\hline & $\begin{array}{l}\text { National Cancer } \\
\text { Center/Cancer Hospital, } \\
\text { China }\end{array}$ & 122 EOC patients & $\begin{array}{l}\text { GDF-15 ELISA } \\
\text { (CICAMS) }\end{array}$ & Serum & $960 \mathrm{pg} / \mathrm{mL}$ & Not applicable & $\begin{array}{l}\text { Serum GDF-15 above threshold } \\
\text { correlates with PFS and } \\
\text { platinum-refractory disease }\end{array}$ & (80) \\
\hline & $\begin{array}{l}\text { Oslo University Hospital, } \\
\text { Ulleval, Norway }\end{array}$ & $\begin{array}{l}312 \text { ovarian cancer } \\
\text { patients }\end{array}$ & $\begin{array}{l}\text { Immunoradiometric } \\
\text { sandwich assay) }\end{array}$ & Plasma & $1,242 \mathrm{pg} / \mathrm{mL}$ & Not applicable & $\begin{array}{l}\text { Plasma GDF-15 above threshold } \\
\text { correlates with shorter OS }\end{array}$ & (102) \\
\hline Ovarian Cancer & $\begin{array}{l}\text { Federal University of } \\
\text { Triângulo Mineiro, Uberaba, } \\
\text { Brazil }\end{array}$ & $\begin{array}{l}38 \text { ovarian cancer } \\
\text { patients }\end{array}$ & $\begin{array}{l}\text { GDF-15 ELISA } \\
\text { (Aviscera Bioscience } \\
\text { Inc.) }\end{array}$ & Serum & Not determined & 59 patients & $\begin{array}{l}\text { Serum GDF-15 levels were } \\
\text { higher in the patients with } \\
\text { malignant neoplasms than in the } \\
\text { patients with benign tumors, yet } \\
\text { the difference was not } \\
\text { statistically significant. GDF-15 } \\
\text { immunostaining was significantly } \\
\text { more frequent in the stroma of } \\
\text { the malignant tumors than in the } \\
\text { stroma of the benign tumors }\end{array}$ & (124) \\
\hline
\end{tabular}


TABLE 1 | Continued

\begin{tabular}{|c|c|c|c|c|c|c|c|c|}
\hline Indication & Patient cohort & Patient numbers & $\begin{array}{l}\text { GDF-15 plasma/ } \\
\text { serum assay }\end{array}$ & Assay matrix & $\begin{array}{l}\text { Plasma/Serum } \\
\text { threshold }\end{array}$ & $\begin{array}{l}\text { GDF-15 expression } \\
\text { tumor (IHC or RNA) }\end{array}$ & $\begin{array}{l}\text { Correlation with clinical } \\
\text { outcome and disease } \\
\text { markers }\end{array}$ & References \\
\hline \multirow[t]{3}{*}{ Prostate cancer } & Cancer Prostate, Sweden & $\begin{array}{l}1,442 \text { prostate cancer } \\
\text { patients }\end{array}$ & $\begin{array}{l}\text { GDF-15 ELISA } \\
\text { (in-house) }\end{array}$ & Serum & $1,466 \mathrm{pg} / \mathrm{mL}$ & Not applicable & $\begin{array}{l}\text { Serum GDF-15 above threshold } \\
\text { correlates with shorter OS }\end{array}$ & $(100)$ \\
\hline & $\begin{array}{l}\text { King George's Medical } \\
\text { University, Lucknow, Center } \\
\text { of Biomedical Research, } \\
\text { SGPGIMS Campus } \\
\text { Lucknow, India }\end{array}$ & $\begin{array}{l}85 \text { prostate cancer } \\
\text { patients }\end{array}$ & $\begin{array}{l}\text { GDF-15 ELISA } \\
\text { (in-house) }\end{array}$ & Serum & Not determined & Not applicable & $\begin{array}{l}\text { GDF-15 correlates with PSA and } \\
\text { Gleason score }\end{array}$ & (85) \\
\hline & $\begin{array}{l}\text { University Hospital Munster, } \\
\text { Germany }\end{array}$ & $\begin{array}{l}38 \text { prostate cancer } \\
\text { patients }\end{array}$ & $\begin{array}{l}\text { GDF-15 ELISA (R\&D } \\
\text { Systems) }\end{array}$ & Serum & $1,300 \mathrm{pg} / \mathrm{mL}$ & Not applicable & $\begin{array}{l}\text { Serum GDF-15 levels were } \\
\text { higher in metastatic than in } \\
\text { non-metastatic patients. Serum } \\
\text { GDF-15 above threshold } \\
\text { correlates with shorter OS }\end{array}$ & (125) \\
\hline $\begin{array}{l}\text { Renal Cell Cancer } \\
\text { (RCC) }\end{array}$ & $\begin{array}{l}\text { University Hospital Munster, } \\
\text { Germany }\end{array}$ & 94 RCC patients & $\begin{array}{l}\text { GDF-15 ELISA (R\&D } \\
\text { Systems) }\end{array}$ & Serum & $1,200 \mathrm{pg} / \mathrm{mL}$ & Not applicable & $\begin{array}{l}\text { Serum GDF-15 is linked to } \\
\text { metastases and relapse. Serum } \\
\text { GDF-15 above threshold } \\
\text { correlates with shorter OS }\end{array}$ & (93) \\
\hline $\begin{array}{l}\text { Urothelial } \\
\text { carcinoma } \\
\text { (UUTUC) }\end{array}$ & $\begin{array}{l}\text { University Hospital Munster, } \\
\text { Germany }\end{array}$ & 38 UUTUC patients & $\begin{array}{l}\text { GDF-15 ELISA (R\&D } \\
\text { Systems) }\end{array}$ & Serum & $1,200 \mathrm{pg} / \mathrm{mL}$ & Not applicable & $\begin{array}{l}\text { Serum GDF-15 is linked to } \\
\text { metastases and relapse. Serum } \\
\text { GDF-15 above threshold } \\
\text { correlates with shorter OS }\end{array}$ & (93) \\
\hline \multirow[t]{2}{*}{$\begin{array}{l}\text { Uveal melanoma } \\
\text { (UM) }\end{array}$} & $\begin{array}{l}\text { University Hospital } \\
\text { Tubingen, Germany }\end{array}$ & $\begin{array}{l}188 \text { uveal melanoma } \\
\text { patients }\end{array}$ & $\begin{array}{l}\text { GDF-15 ELISA (R\&D } \\
\text { Systems) }\end{array}$ & Serum & Not determined & $\begin{array}{l}\text { GDF-15 IHC of } 44 \text { UM } \\
\text { patients }\end{array}$ & $\begin{array}{l}\text { Patients with clinically detectable } \\
\text { metastases had significantly } \\
\text { higher GDF-15 serum levels } \\
\text { compared to those without } \\
\text { clinically detectable metastases } \\
\text { as well as to healthy individuals }\end{array}$ & $(101)$ \\
\hline & $\begin{array}{l}\text { The Johns Hopkins } \\
\text { Hospital, USA }\end{array}$ & $\begin{array}{l}48 \text { uveal melanoma } \\
\text { patients }+36 \text { healthy } \\
\text { controls }\end{array}$ & $\begin{array}{l}\text { GDF-15 Bio-Plex } \\
\text { (BioRad) }\end{array}$ & Serum & Not determined & Not applicable & $\begin{array}{l}\text { GDF-15 + MIA proposed to } \\
\text { discriminate between patients } \\
\text { with metastatic uveal melanoma } \\
\text { and disease-free patients [AUC } \\
=0.85(0.68-1.00), \text { n.s.] }\end{array}$ & $(126)$ \\
\hline $\begin{array}{l}\text { Solid vs. non-solid } \\
\text { treatment-naive } \\
\text { malignancies }\end{array}$ & Vienna General Hospital & $\begin{array}{l}555 \text { treatment-naive } \\
\text { cancer patients (breast } \\
\text { cancer, lung cancer, } \\
\text { gastrointestinal cancer } \\
\text { and hematological } \\
\text { cancers) }\end{array}$ & $\begin{array}{l}\text { GDF-15 ELISA (R\&D } \\
\text { Systems) }\end{array}$ & Serum & $\begin{array}{l}\text { Tertiles of GDF-15 } \\
\text { level }\end{array}$ & Not applicable & $\begin{array}{l}\text { GDF-15 is significantly } \\
\text { associated with outcome for } \\
\text { solid tumors as breast cancer, } \\
\text { lung cancer or gastrointestinal } \\
\text { cancer; however, no association } \\
\text { with outcome could be shown } \\
\text { for hematological cancers as } \\
\text { myelodysplastic or } \\
\text { myeloproliferative diseases }\end{array}$ & $(127)$ \\
\hline
\end{tabular}




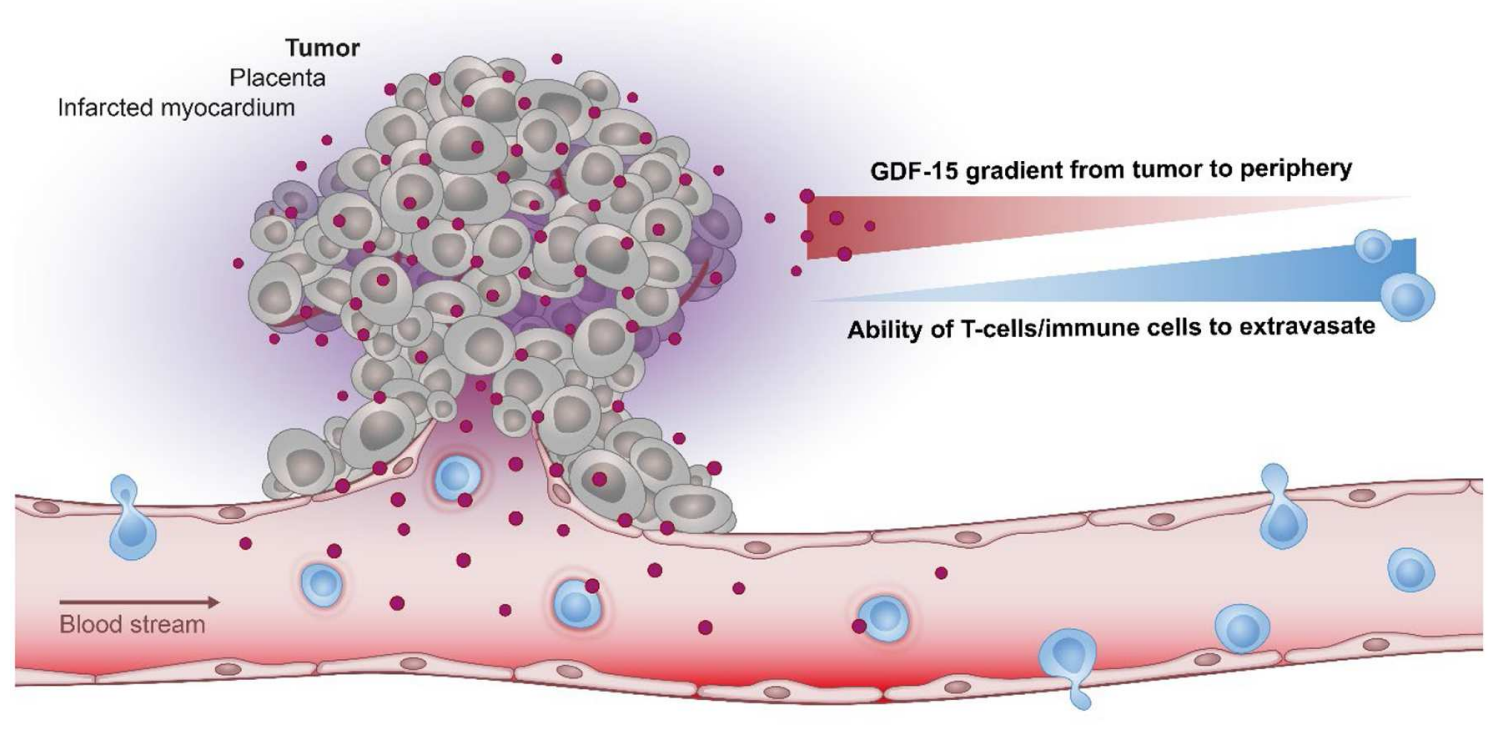

FIGURE 2 | The role of GDF-15 in immune modulation. In various pathological conditions, GDF-15 correlates inversely with the ability of T cell to infiltrate the tumor, placenta, or the infarcted myocardium. As the most prominent physiological expression of GDF-15 is found in the placenta it may have evolved to protect the (semi-allogeneic) fetus by establishing a protective barrier at the placenta-fetal junction, thus shielding the fetus against maternal $T$ cells.

center of the tumor. Moreover, the presence of tumor-adjacent organized lymphoid aggregates and the type of inflammatory context are also strongly linked to outcome (139).

Based on its ability to shield tissues against inflammation (Figure 2), GDF-15 may thus be expected to change the immune contexture within a tumor. In line with this hypothesis, an observational study reported an inverse correlation between elevated GDF-15 expression and the presence of a Crohn'slike type of mononuclear infiltrate (113). Interestingly, this negative correlation was not found in a subgroup of patients with an allelic variation in GDF-15, indicating that immune exclusion in GDF-15 overexpressing tumors might be linked to functional properties of the most common GDF-15 allele. A further study in transplantable glioblastoma revealed that shRNA-mediated downregulation of GDF-15 increased T cell infiltration into tumors, improved immune responses and prolonged survival (140).

GDF-15 was further identified in an unbiased screening for tumor-derived factors that suppress dendritic cell function. Functional assays showed GDF-15 to be a potent suppressor of dendritic cell maturation that inhibits expression of costimulatory and major histocompatibility complex (MHC) class II molecules, reduces IL-12 levels and elevates TGF- $\beta 1$ secretion. Thus, GDF-15 may promote immune escape of tumor cells by inhibiting $\mathrm{T}$ cell stimulation and cytotoxic $\mathrm{T}$ lymphocyte activation by dendritic cells (99). Similar to macrophages in white adipose tissue $(52,57)$ also macrophages in the tumor microenvironment adopt a tolerogenic/immunosuppressive phenotype when exposed to GDF-15. Depletion of tumorderived GDF-15 in an orthotopic pancreatic cancer model and in Ras-driven tumor xenografts hence restored the immune surveillance function of tumor-infiltrating macrophages, resulting in improved tumor control (108). Thus, a role for GDF15 in tumor immune escape is supported by many studies. Still, there is no consensus regarding the underlying mechanism(s).

\section{Mechanisms of Action}

With such a broad spectrum of functions across tissues and cellular functions (Figure 1), it is crucial to identify the mode of action of GDF-15, its interacting receptors, and their downstream signaling pathways. The recognition of GDF-15 as an important regulator of body weight (35) has initiated a search to identify its potential partnering receptor and the resulting signaling pathways. From earlier studies, it was postulated that the signaling pathway of GDF-15 would be through SMAD2/3 interacting with the receptor TGFBRII $(64,141,142)$. In the four independent studies which identified GFRAL to be the receptor responsible for the metabolic effects of GDF-15, binding of GDF15 to members of the TGF- $\beta$ receptor superfamily was thus carefully evaluated (28-30). However, binding of ${ }^{125}$ I-labeled GDF-15 (30 pM) to COS7 cells transfected with combinations of type I and type II TGF $\beta$ family receptors (30); flow cytometrybased binding assays using biotinylated GDF-15 on HEK cells transfected with GFRAL and all 139 other molecules related to the TGF- $\beta$ receptor superfamily (41); and cell-based PathHunter Dimerization assays on more than 20 potential TGF- $\beta$-family receptor pairs (29) all failed to show any binding of GDF-15 to a TGF- $\beta$ receptor. Thus, for now the GDNF receptor family member GFRAL remains the only validated GDF-15 receptor (143). Like other members of the GDNF receptor family, GFRAL interacts with its co-receptor RET (most efficiently with RET51) and signals via the extracellular-signal related kinase (ERK) and AKT/protein kinase B pathways, without activating canonical TGF- $\beta$ signaling pathways. 
Very importantly, several authors have reported that commercially available GDF-15 preparations are often contaminated with variable bioactive levels of TGF$\beta 1 \quad((15,26,27)$ and others [Pierre Coulie, personal communication]). Signal transduction through SMAD2/3 or via TGF $\beta$ RII interaction may thus be artifacts caused by contaminating TGF- $\beta 1$ rather than by $\operatorname{GDF}-15$ itself $(7,52,144)$. Therefore, studies reporting TGF- $\beta$ related effects induced by recombinant human GDF-15 need to be regarded with great caution. Consequently, this review largely focusses on findings from genetic in vivo models and on ex vivo analyses from human samples. Still, there remains substantial evidence for direct effects of GDF-15 on leukocytes. Given that GFRAL expression is restricted to brainstem neurons, binding of GDF15 to GFRAL cannot account for these immunomodulatory effects of GDF-15. Experiments comparing immunological alterations in GDF-15 knock-out mice vs. GFRAL knock-out mice would be a straightforward approach to clarify whether GFRAL-independent effects of GDF-15 exist.

Interestingly, a GFRAL- and CNS-dependent metabolic loop has been identified by which GDF-15 induces disease tolerance largely independent of pathogen control or the magnitude of inflammatory response (68). Instead, the authors propose that GDF-15 acts as an inflammation-associated hormone, coordinating tolerance to inflammatory damage through regulation of hepatic triglyceride metabolism. While this links the tissue-protective function of GDF-15 to its wellunderstood metabolic effects, the proposed loop places any effect of GDF-15 downstream of a systemic metabolic shift. This proposed mechanism thus cannot account for local or fast-acting effects of GDF-15. Similarly, the role of GDF-15 in shaping the tumor microenvironment at very early tumor stages (108) is unlikely to be attributable to a CNS-mediated systemic change of metabolism. In consideration of the substantial amount of data describing anti-inflammatory functions of GDF-15 $(63,66)$, the inability of GDF-15 to modulate the extent of inflammation in the chosen sepsis model is also surprising. Possibly, the inflammatory burst in the chosen model was strong enough to overrule local immune-inhibitory effects of GDF-15, thus revealing a secondary systemic level of GDF-15 dependent tissue protection.

\section{Signaling of GDF-15 in Cancer Cells}

Given the very limited tissue distribution of GFRAL (28-30, 41), direct effects of GDF-15 on cancer or immune cells are likely to be mediated via GFRAL-independent signaling pathways. With regard to tumor cells, GDF-15 has been implicated in suppression or stimulation of tumor cell apoptosis, in early tumorigenesis, in epithelial-to-mesenchymal transition (EMT), in stemness, chemo-resistance, angiogenesis invasion, and metastasis [review by Modi et al. (25)]. Signaling mechanisms ascribed to GDF-15 in various carcinomas do not only involve Smad 2/3 signaling, which could also be attributable to contaminating TGF- $\beta$ in preparations of GDF-15, but also IGFR1, PI3K, Akt, ERK1/2, $\beta$ catenin, p38, MAPK, Smad1/5/8, NF-кB, reactive oxygen species, mTOR, FAK-RhoA, EGFR, ErbB2, and c-myc signaling (among others). An understanding of which pathway is activated in which cell type or situation is, unfortunately, completely lacking.
In breast cancer, where GDF-15 has been linked to metastasis and to resistance toward trastuzumab, the following signaling pathways were suggested for GDF-15: Signaling via Smad $1 / 5 / 8$ leading to up-regulation of hepcidin (145); induction of IGF1R-FoxM1 signaling leading to activation of Snail and Slug, epithelial-to-mesenchymal transition and MMP2/9-mediated cellular invasion (109); triggering of HER2-independent, TGFRand Src-dependent phosphorylation of the HER2-Akt-Erk1/2 axis $(146,147)$; activation of p38 MAPK (148) and of JNK mitogen-activated protein kinases (MAPKs) (149) resulting in enhanced invasion of HER2-positive cancer cells. In contrast, another study found inhibition of invasion and of metastasis via activation of the Yes associated protein (YAP) leading to (YAP)-dependent transcriptional repression (150).

In cervical cancer cell lines, GDF-15 was found to act through a complex with ErbB2, thereby stimulating PI3K, AKT1, Erk1/2, and Ras-GTP signaling. Enhanced cell proliferation and upregulation of cdc25A, CDK2, CDK4, CyclinD1, CyclinE1, as well as down-regulation of p21 were found to be FOXO1and c-Myc-dependent (151). In lung cancer cells, GDF-15 was described to inhibit rather than activate the p38-MAPK (152) and the PI3K-Akt-PKB and ERK1/2 pathways (153), resulting in enhanced apoptosis. In colorectal cancer, where clinical data have established a strong link between GDF-15 expression and poor survival, GDF-15 is reported to induce EMT-related factors (154) and to enhance metastasis (78). Another study has, however, described GDF-15 dependent induction of apoptosis in colorectal cancer cells and suggested GDF-15 to act as a tumor suppressor (155).

In prostate cancer, where GDF-15 expression was also found in tumor-associated fibroblasts, GDF-15 was positively associated with tumor cell proliferation, cancer progression and anchorage-independent growth (156-158). Proposed mechanisms include activation of FAK-RhoA signaling leading to actin rearrangement and enhanced cell motility, invasion and metastasis (159) and dysregulation of maspin, matriptase, and IL-6 (157). In ErbB2-overexpressing gastric cancer cells, GDF-15 was found capable of transactivating EGFR family tyrosine kinases leading to Akt and ERK-1/2 phosphorylation and enhanced invasion. Further, ERK-dependent induction of urokinase-type plasminogen activator and urokinase type plasminogen activator receptor was reported, again leading to enhanced metastasis (146). Others, again, observed induction of apoptosis by GDF-15 in gastric cancer cells (160). In hepatocellular carcinoma, GDF-15 was found to enhance cell viability, invasion, metastasis (79), and hepatitis $\mathrm{C}$ virus (HCV) replication (161). Findings for hepatocellular carcinoma also include pro-apoptotic/anti-tumor effects of GDF-15, whereby GDF-15 has been linked to inhibition of Bcl-2 and Bcl-xL, upregulation of Bax, activation of pro-caspase 3, 8, and 9, and PARP (poly (ADP-ribose) polymerase) cleavage (162-164). In stem cells derived from hepatocellular cancer, GDF-15 induced AKT/GSK-3 $\beta / \beta$-catenin signaling, which would, again, be tumor-promoting (165).

In MyD88-positive type I epithelial ovarian cancer cells, GDF-15 induced NF- $\mathrm{B}$ signaling in vitro, thereby up-regulating stemness markers (OCT-4, SOX-2) and chemokine expression 
(CXCL-1, IL-8, and MCP-1) (166). In other studies on ovarian cancer cells, GDF-15 was found to signal via PI3K/mTOR, MAP kinases, phosphorylation of $\mathrm{p} 38$, Akt, and $4 \mathrm{EBP} 1$ to promote proliferation, anchorage-independent growth, invasion and upregulation of matrix metalloproteinases $\mathrm{MMP} 2 / 9$ and vascular endothelial growth factor (VEGF) (167). GDF-15 has also been found to functionally contribute to platinum resistance (168). In immortalized oral mucosal and oral squamous cell carcinoma (OSCC) cell lines, GDF-15 overexpression also resulted in increased phosphorylation of Akt and ERK1/2 and significant induction of cell proliferation, migration, invasion, and colony formation (169). In addition, GDF-15 increased radio-resistance of OSCC (170), most likely by reducing intracellular reactive oxygen species (171). Anti-apoptotic activity of GDF-15 was shown in vitro, where overexpression of GDF-15 reduced caspase 3/7 activity and knockdown of GDF-15 increased the level of cleaved PARP and BAX (98). Paradoxically, GDF-15 was also reported to enhance apoptotic effects of tolfenamic acid (TA) via increased caspase- 3 cleavage and cleaved poly(ADP-ribose) polymerase (PARP) in HNC cells (172).

In melanoma where GDF-15 expression is induced by oncogenic V600EB-Raf (119) and by microphthalmiaassociated transcription factor (MITF) (120), GDF-15 may be involved in angiogenesis (119). Knockdown experiments in pancreatic cancer cells showed GDF-15 to be an effector of Twist-mediated changes, including enhanced invasion and chemoresistance (173). In glioma cells, RNAi-mediated GDF-15 depletion inhibited tumor cell proliferation and enhanced immunogenicity, immune infiltration, and survival in a syngeneic mouse model (140).

Thus, in vitro and in vivo studies suggest that the effects of GDF-15 on cancer cells are manifold, even when no GFRALexpressing neuronal cells are present. As opposed to the evident epidemiological data linking GDF-15 with poor survival, studies exploring autocrine effects in tumor cells have, however, reached no consensus as to whether GDF-15 acts as a tumor promoter or suppressor. An understanding of which of the possible signaling pathways is likely to be activated by GDF-15 in a specific situation is also lacking and difficult to predict, since key pieces of the puzzle are still missing. It is unclear whether these diverse outcomes ensue from cell-intrinsic signaling, which is instigated by GDF-15's action on tumor cells. Alternatively, the highly context-dependent findings might best be explained by GDF15 's action on the tissue context of the tumor cells, i.e., the tumor microenvironment.

\section{Signaling of GDF-15 in the Tumor Microenvironment}

The tumor microenvironment is typically composed of non-malignant cells, including fibroblasts, vascular cells, lymphatic vessels, and immune cells of lymphoid or myeloid origin. It provides a niche for tumor cells, protecting them against immunosurveillance and enabling them to retain a dedifferentiated, stem cell-like state. The various reports on GDF-15 promoting stemness in cancer cells $(96,165,166,171)$ might thus be explained by GDF-15 shaping the tumor microenvironment. Moreover, the diagnostically most essential cells in the tumor microenvironment are immune cells. It is now clear that changes in the immune contexture of a tumor have a significant impact on the biological behavior of cancers and on patient survival (136). Context-dependent strong effects of GDF-15 could thus be explained by GDF-15 inducing changes in the immune contexture. Thus, the GFRAL- and hepatic triglyceride-dependent tissue-protective effect (68) could also support the survival of neoplastic tissue when attacked by an immune response and thereby change the delicate balance between tumor and immune cells.

As outlined above, there is also ample evidence for direct effects of GDF-15 on immune cells. These effects include the well-documented function of GDF-15 as immune cell repellent $(63,66,73,140)$ (Figure 2), which can be explained by GDF15 inhibiting the conformational activation of the integrin LFA1 (lymphocyte function-associated antigen 1, $\alpha \mathrm{L} \beta 2$-integrin, CD11a/CD18). However, while the initial observation that GDF15 interferes with LFA-1 dependent recruitment of inflammatory cells was convincingly shown in vivo (66), a subsequent study suggesting that these effects would be mediated through the ALK-5/TGF- $\beta$ RII heterodimer (142) may have been affected by use of contaminated reagents $(27,29,30,41)$. Still, the mechanistic data generated with knock-out and heterozygous mice remain valid. Furthermore, the key role of LFA-1 at the immunological synapse (174) would predict that GDF-15's role is not restricted to immune cell recruitment $(63,66,73,113$, 140). Inhibition of LFA-1 by GDF-15 would also impair the priming of antigen-specific $\mathrm{T}$ cells by dendritic cells. Such functional outcomes were independently observed in other studies $(99,175)$. The latter study also found that a knockout of GDF-15 in immature dendritic cells promotes their maturation and enhances their immune stimulatory potential. Transgenic expression of GDF-15 in dendritic cells, in contrast, induces immune-inhibitory molecules in dendritic cells which then enhance $\mathrm{T}$ cell exhaustion and promote the generation of regulatory $\mathrm{T}$ cells. Mechanistically, the observed GDF-15 mediated induction of a tolerogenic dendritic cell phenotype was found to depend on TGF- $\beta$ receptors I and II (rather than on GFRAL), on repression of malate-1 circular RNA expression, on inhibition of NF- $\kappa \mathrm{B}$ signaling, and on the induction of indoleamine-2,3-dioxygenase (IDO1) in dendritic cells (175). Effects of GDF-15 on LFA-1 were not investigated and possible problems resulting from the use of recombinant human GDF-15 (which may have contained TGF- $\beta$ ) were not discussed. Still, the in vivo findings appear convincing and impressive.

Another study based on pancreatic cancer models indicated that tumor cells use GDF-15 during the early stages of tumorigenesis to evade macrophage-mediated immune surveillance. Mechanistically, tumor-derived GDF-15 was reported to suppress proapoptotic macrophage activity by

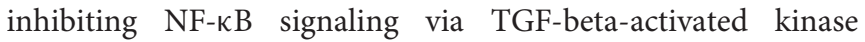
(TAK1), thereby blocking the synthesis of TNF- $\alpha$ and nitric oxide (NO) production (108). Thus, different studies suggest different mechanisms to explain the effects of GDF-15 on immune cells. There is, however, a consensus that GDF-15 inhibits immune responses at different levels. Further, there is 
evidence for inhibitory effects on immune cell recruitment, on the function of antigen-presenting cells and on macrophage polarization. Thus, the different reports appear complementary rather than contradictory.

Perceiving GDF-15 as an anti-inflammatory molecule in cancer may then also explain paradoxical findings of GDF15 overexpression on prostate cancer development and spread. In the TRAMP transgenic model of spontaneous prostate cancer, transgene-mediated overexpression of GDF-15 reduced the growth of the primary tumor (176). As tumor-promoting inflammation (which has been declared a hallmark of cancer since 2011) (134) critically contributes to spontaneous tumor development in this model $(177,178)$, suppression of tumor growth by GDF-15 may be explained by its anti-inflammatory effects. Metastasis is, however, limited by immune surveillance in this (179) and in many other tumor models (179-183). Since GDF-15 transgenic mice developed more lung metastases and distant organ metastases, metastasis formation does not seem to depend on the size of the primary tumor. Instead, metastasis may be facilitated by effects of GDF-15 on immunosurveillance (176). Likewise in patients, where larger-sized prostate tumors can be resected, while metastasis is a deadly threat, the pro-metastatic effects of GDF-15 overexpression are likely more relevant than its tumor-suppressive properties. This is strongly supported by epidemiological data, which shows that GDF-15 is a risk factor for metastasis and death from prostate cancer $(83,85,100,184)$. Overall, the role of GDF-15 in the tumor microenvironment as currently understood, leads to reasonably consistent explanations for the experimental and epidemiological findings on GDF-15 in cancer.

\section{GDF-15 as a Therapeutic Target for the Treatment of Solid Tumors}

The interest in GDF-15 as a target for weight and appetite regulation is reflected by the four independent pharma-driven studies that revealed GFRAL to be the GDF-15 receptor responsible for its metabolic effects $(28-30,41)$. In consideration of the enormous potential of GFRAL modulators to counteract overeating and obesity, the GDF-15/GFRAL/RET pathway is the most active area for drug development in this endeavor. It would thus be surprising if GDF-15/GFRAL/RET inhibitors were not simultaneously developed for the treatment of cancer. However, the finding that loss of muscle mass depends on GDF11 , whereas GDF-15 is mainly responsible for anorexia, would seem to indicate that such drugs would be of limited usefulness in cancer patients with wasting syndrome (43). Still, anti-GDF15 antibodies or GFRAL inhibitors may show at least substantial palliative benefit. Treatments that improve the general fitness of cancer patients can also support other treatments (32). Consequently, these findings alone are deemed sufficient to develop GDF-15 as therapeutic target. Another advantage is the ease of measuring GDF-15 serum levels for efficient patient stratification during clinical development (185).

An interesting aspect was added by a recent study demonstrating that $\beta$-adrenergic signaling initiated by the
GDF-15/GFRAL/RET pathway stimulates the release of tissueprotective hepatic triglycerides (68). It remains to be tested whether this $\beta$-adrenergic signaling also protects cancer tissues against the challenges associated with inflammation. If this were indeed confirmed, anti-GDF-15 antibodies or GFRAL inhibitors would have the potential to synergistically boost the effects of chemo-, radiation- or immunotherapy.

Reported tumor suppressor functions of GDF-15 mostly occur during the early phases of tumor development and appear to be restricted to the primary tumor (176). These effects during the early phases of tumor development are of lesser concern for patients who require new treatment modalities due to advanced, metastatic or at least micro-metastatic cancer. Still, it should be explored whether such tumor-suppressive effects can be explained by GDF-15 inhibiting tumor-promoting inflammation, which would be in line with the known functions of GDF-15 and help to provide a conceptual understanding for risk assessment.

The neutralization of the anti-inflammatory functions of GDF-15 could potentially enhance tumor-promoting inflammation. However, converting a non-inflamed into an inflamed tumor would be highly desirable in the context of cancer immunotherapy. Indeed, by inhibiting dendritic cell maturation and by preventing immune cell recruitment, GDF-15 interferes with priming of $\mathrm{T}$ cells by dendritic cells and with infiltration of activated T cells into the tumor microenvironment $(63,66,73,140)$. GDF-15 thus impairs two essential steps in the so-called Cancer Immunity Cycle (186). Of note, GDF15 's potential role in the exclusion of $\mathrm{T}$ cells from the tumor microenvironment would be consistent with its preferential expression in solid tumors as opposed to hematological malignancies (Figure 2).

The consistently negative correlation between GDF-15 expression and patient survival is consistent with the detrimental impact of immune exclusion on survival (135). Importantly, tumors that are devoid of infiltrating $\mathrm{T}$ cells cannot respond to therapies like PD-1 based immune checkpoint blockade (187189). The conversion of such immune-excluded or immuneneglected "cold" tumors into well-infiltrated, inflamed, "hot" tumors that are accessible for immunotherapies is therefore of significant interest (190). Moreover, as T cells in the tumor microenvironment often acquire an epigenetically imprinted irreversibly exhausted state (191), recruitment of fresh T cells may be generally required to achieve immune-mediated tumor control $(189,191)$. Since neutralizing GDF-15 could "heat up" the tumor microenvironment, it may already achieve a benefit in monotherapy $(135,181)$.

Further options arise from GDF-15 inhibition in combination with immune checkpoint blockade, vaccination (192), adoptive transfer of gene-modified T cells (193), and other immunotherapies. In this regard, studies are underway to correlate serum GDF-15 concentrations in cohorts of patients with response or lack of response to $\mathrm{PD}-(\mathrm{L}) 1$ checkpoint inhibitors. While it is already clear that cancer types with the reportedly highest levels of GDF-15 are less prone to benefit from such single-agent immunotherapies, a possible role for GDF-15 in the evolving landscape of biomarkers for checkpoint inhibitor immunotherapy (194) remains to be established. A 
recent meta-analysis on biomarker modalities for predicting response to PD-1/PD-L1 checkpoint blockade confirmed that immune cell infiltration is a stronger predictor of response than PD-L1 expression, gene expression profiles or tumor mutational burden (188). The ability of GDF-15 to exclude immune cells from infiltrating a tissue thus warrants further investigation in the context of immune checkpoint inhibition.

Stress-induced GDF-15 production is sufficient to exclude immune cells from the liver (63). This observation could explain why liver metastases are the worst predictors for the success of cancer immunotherapy, as liver metastases hardly ever respond to immunotherapy (195). Neutralization of GDF-15 activity could thus also be a viable approach to extend the benefits of immunotherapy to patients with liver metastases. Overall, there are numerous options for exploring the potential of GDF-15 inhibitors in cancer immunotherapy. As there is no evidence for GFRAL expression in immune cells, the effects of GDF15 on dendritic cell maturation and immune cell infiltration may be mediated by another still unknown receptor. Thus, it is unclear whether GFRAL inhibitors, which are being developed and tested to treat cancer anorexia (clinical trial identifier NCT04068896), could be a valid alternative to anti-GDF-15 antibodies for immunotherapy.

\section{CONCLUSION}

GDF-15 is among the most widely overexpressed proteins in human cancer (20). High GDF-15 serum levels are invariably associated with poor prognosis. Functionally, GDF-15 is a main culprit for anorexia in cancer patients (32). Its involvement in muscle wasting has, however, recently been questioned (43). By stimulating hepatic triglyceride release, GDF-15 helps tissues to survive inflammatory stress (68).

Reports on GDF-15-dependent effects in cancer cells are numerous, but the range of reported effects is complex, diverse, and inconsistent, with no consensus in sight. The

\section{REFERENCES}

1. Bootcov MR, Bauskin AR, Valenzuela SM, Moore AG, Bansal M, He XY, et al. MIC-1, a novel macrophage inhibitory cytokine, is a divergent member of the TGF-beta superfamily. Proc Natl Acad Sci USA. (1997) 94:11514-9. doi: 10.1073/pnas.94.21.11514

2. Hromas R, Hufford M, Sutton J, Xu D, Li Y, Lu L. PLAB, a novel placental bone morphogenetic protein. Biochim Biophys Acta. (1997) 1354:40-4. doi: 10.1016/S0167-4781(97)00122-X

3. Lawton LN, Bonaldo MF, Jelenc PC, Qiu L, Baumes SA, Marcelino RA, et al. Identification of a novel member of the TGF-beta superfamily highly expressed in human placenta. Gene. (1997) 203:17-26. doi: 10.1016/S0378-1119(97)00485-X

4. Böttner M, Laaff M, Schechinger B, Rappold G, Unsicker K, SuterCrazzolara C. Characterization of the rat, mouse, and human genes of growth/differentiation factor-15/macrophage inhibiting cytokine-1 (GDF15/MIC-1). Gene. (1999) 237:105-11. doi: 10.1016/S0378-1119(99)00309-1

5. Ulirsch JC, Lacy JN, An X, Mohandas N, Mikkelsen TS, Sankaran VG. Altered chromatin occupancy of master regulators underlies evolutionary divergence in the transcriptional landscape of erythroid differentiation. PLoS Genet. (2014) 10:e1004890. doi: 10.1371/journal.pgen.1004890 literature is further marred by artifacts, as a leading commercial source of recombinant GDF-15 was shown to be unfortunately contaminated with bioactive concentrations of TGF- $\beta 1$ (27).

A more consistent pattern emerges from the literature on the immunomodulatory functions of GDF-15. In line with its presumed physiological role in protecting a semi-allogeneic fetus from the maternal immune system (45), GDF-15 suppresses essential arms of the immune response. Best documented are effects on antigen presentation by dendritic cells $(99,175)$ and on immune cell trafficking $(63,66,73,140)$. Available data suggest that neutralizing GDF-15 has the potential to not only ameliorate anorexia in cancer patients, but also to improve immunotherapies $(108,140)$. Given the limited sequence homology between humans and mice, it is not clear whether mouse experiments can fully resolve the still open questions. Based on the clinical correlations and the mechanistic understanding, clinical trials testing anti-GDF-15 treatments appear promising, specifically in patients with elevated GDF15 serum levels. Considering the mild phenotype of GDF15 knock-out mice, good tolerability can be expected. Recent disappointing results obtained with combinations of drugs which all aim to rescue the cytolytic effector capacity of T cells (196) further suggest that the targeting of different mechanisms may be required to achieve better synergy. In this regard the "immune cell repellent" GDF-15 which acts at a critical stage of the antitumor immune response not addressed by other checkpoints (186) represents a most promising target. Inhibiting an immune evasion mechanism that is potent enough to protect a semiallogeneic fetus from rejection by the maternal immune system certainly holds potential to improve immune responses against neoantigen-bearing tumor cells $(191,197)$.

\section{AUTHOR CONTRIBUTIONS}

JW wrote the article as lead author. IM and WF brought in their specific expertise and contributed to writing as co-authors.

6. Bauskin AR, Jiang L, Luo XW, Wu L, Brown DA, Breit SN. The TGFbeta superfamily cytokine MIC-1/GDF15: secretory mechanisms facilitate creation of latent stromal stores. J Interferon Cytokine Res. (2010) 30:389-97. doi: 10.1089/jir.2009.0052

7. Li J, Liu J, Lupino K, Liu X, Zhang L, Pei L. Growth differentiation factor 15 maturation requires proteolytic cleavage by PCSK3,-5, and-6. Mol Cell Biol. (2018) 38:e0249-18. doi: 10.1128/MCB.00249-18

8. Li S, Wang Y, Cao B, Wu Y, Ji L, Li YX, et al. Maturation of growth differentiation factor 15 in human placental trophoblast cells depends on the interaction with matrix metalloproteinase-26. J Clin Endocrinol Metab. (2014) 99:E2277-87. doi: 10.1210/jc.2014-1598

9. Abd El-Aziz SH, Endo Y, Miyamaori H, Takino T, Sato H. Cleavage of growth differentiation factor 15 (GDF15) by membrane type 1-matrix metalloproteinase abrogates GDF15-mediated suppression of tumor cell growth. Cancer Sci. (2007) 98:1330-5. doi: 10.1111/j.1349-7006.2007.00547.x

10. Min KW, Liggett JL, Silva G, Wu WW, Wang R, Shen RF, et al. NAG$1 /$ GDF15 accumulates in the nucleus and modulates transcriptional regulation of the smad pathway. Oncogene. (2016) 35:377-88. doi: 10.1038/onc.2015.95

11. Kamiya R, Asakura S. Helical transformations of Salmonella flagella in vitro. J Mol Biol. (1976) 106:167-86. doi: 10.1016/0022-2836(76)90306-5 
12. Xiong Y, Walker K, Min X, Hale C, Tran T, Komorowski R, et al. Long-acting MIC-1/GDF15 molecules to treat obesity: evidence from mice to monkeys. Sci Transl Med. (2017) 9:eaan8732. doi: 10.1126/scitranslmed.aan8732

13. Nazarova NY, Chikhirzhina GI, Tuohimaa P. Calcitriol induces transcription of the placental transforming growth factor $\beta$ gene in prostate cancer cells via an androgen-independent mechanism. Mol Biol. (2006) 40:72-6. doi: 10.1134/S0026893306010110

14. Uhlen M, Fagerberg L, Hallstrom BM, Lindskog C, Oksvold P, Mardinoglu A, et al. Tissue-based map of the human proteome. Science. (2015) 347:1260419. doi: 10.1126/science.1260419

15. Tsai VWW, Husaini Y, Sainsbury A, Brown DA, Breit SN. The MIC1/GDF15-GFRAL pathway in energy homeostasis: implications for obesity, cachexia, and other associated diseases. Cell Metab. (2018) 28:353-68. doi: 10.1016/j.cmet.2018.07.018

16. Adela R, Banerjee SK. GDF-15 as a target and biomarker for diabetes and cardiovascular diseases: a translational prospective. J Diabetes Res. (2015) 2015:490842. doi: 10.1155/2015/490842

17. Guenancia C, Kahli A, Laurent G, Hachet O, Malapert G, Grosjean S, et al. Pre-operative growth differentiation factor 15 as a novel biomarker of acute kidney injury after cardiac bypass surgery. Int J Cardiol. (2015) 197:66-71. doi: 10.1016/j.ijcard.2015.06.012

18. Wiklund FE, Bennet AM, Magnusson PK, Eriksson UK, Lindmark $\mathrm{F}, \mathrm{Wu} \mathrm{L}$, et al. Macrophage inhibitory cytokine-1 (MIC-1/GDF15): a new marker of all-cause mortality. Aging Cell. (2010) 9:1057-64. doi: 10.1111/j.1474-9726.2010.00629.x

19. Strelau J, Strzelczyk A, Rusu P, Bendner G, Wiese S, Diella F, et al. Progressive postnatal motoneuron loss in mice lacking GDF-15. J Neurosci. (2009) 29:13640-8. doi: 10.1523/JNEUROSCI.1133-09.2009

20. Welsh JB, Sapinoso LM, Kern SG, Brown DA, Liu T, Bauskin AR, et al. Large-scale delineation of secreted protein biomarkers overexpressed in cancer tissue and serum. Proc Natl Acad Sci USA. (2003) 100:3410-5. doi: 10.1073/pnas.0530278100

21. Uhlen M, Zhang C, Lee S, Sjöstedt E, Fagerberg L, Bidkhori G, et al. A pathology atlas of the human cancer transcriptome. Science. (2017) 357:eaan2507. doi: 10.1126/science.aan2507

22. Cerami E, Gao J, Dogrusoz U, Gross BE, Sumer SO, Aksoy BA, et al. The cBio cancer genomics portal: an open platform for exploring multidimensional cancer genomics data. Cancer Discov. (2012) 2:401-4. doi: 10.1158/2159-8290.CD-12-0095

23. Gao J, Aksoy BA, Dogrusoz U, Dresdner G, Gross B, Sumer SO, et al. Integrative analysis of complex cancer genomics and clinical profiles using the cBioPortal. Sci Signal. (2013) 6:pl1. doi: 10.1126/scisignal.20 04088

24. Mimeault M, Batra SK. Divergent molecular mechanisms underlying the pleiotropic functions of macrophage inhibitory cytokine-1 in cancer. J Cell Physiol. (2010) 224:626-35. doi: 10.1002/jcp.22196

25. Modi A, Dwivedi S, Roy D, Khokhar M, Purohit P, Vishnoi J, et al. Growth differentiation factor 15 and its role in carcinogenesis: an update. Growth Fact. (2019) 37:190-207. doi: 10.1080/08977194.2019.1685988

26. Breit SN, Tsai VW, Brown DA. Targeting obesity and cachexia: identification of the GFRAL receptor-MIC-1/GDF15 pathway. Trends Mol Med. (2017) 23:1065-7. doi: 10.1016/j.molmed.2017.10.005

27. Olsen OE, Skjaervik A, Stordal BF, Sundan A, Holien T. TGF-beta contamination of purified recombinant GDF15. PLoS ONE. (2017) 12:e0187349. doi: 10.1371/journal.pone.0187349

28. Emmerson PJ, Wang F, Du Y, Liu Q, Pickard RT, Gonciarz MD, et al. The metabolic effects of GDF15 are mediated by the orphan receptor GFRAL. Nat Med. (2017) 23:1215-9. doi: 10.1038/nm.4393

29. Mullican SE, Lin-Schmidt X, Chin CN, Chavez JA, Furman JL, Armstrong AA, et al. GFRAL is the receptor for GDF15 and the ligand promotes weight loss in mice and nonhuman primates. Nat Med. (2017) 23:1150-7. doi: $10.1038 / \mathrm{nm} .4392$

30. Hsu JY, Crawley S, Chen M, Ayupova DA, Lindhout DA, Higbee J, et al. Nonhomeostatic body weight regulation through a brainstem-restricted receptor for GDF15. Nature. (2017) 550:255-9. doi: 10.1038/nature24042

31. Mullican SE, Rangwala SM. Uniting GDF15 and GFRAL: therapeutic opportunities in obesity and beyond. Trends Endocrinol Metab. (2018) 29:560-70. doi: 10.1016/j.tem.2018.05.002

32. Lerner L, Hayes TG, Tao N, Krieger B, Feng B, Wu Z, et al. Plasma growth differentiation factor 15 is associated with weight loss and mortality in cancer patients. J Cachexia Sarcopenia Muscle. (2015) 6:317-24. doi: $10.1002 /$ jcsm. 12033

33. Patel S, Alvarez-Guaita A, Melvin A, Rimmington D, Dattilo A, Miedzybrodzka EL, et al. GDF15 provides an endocrine signal of nutritional stress in mice and humans. Cell Metab. (2019) 29:707-18 e708. doi: 10.1016/j.cmet.2018.12.016

34. Neary NM, Goldstone AP, Bloom SR. Appetite regulation: from the gut to the hypothalamus. Clin Endocrinol. (2004) 60:153-60. doi: 10.1046/j.1365-2265.2003.01839.x

35. Johnen H, Lin S, Kuffner T, Brown DA, Tsai VW, Bauskin AR, et al. Tumorinduced anorexia and weight loss are mediated by the TGF-beta superfamily cytokine MIC-1. Nat Med. (2007) 13:1333-40. doi: 10.1038/nm1677

36. Tsai VWW, Lin S, Brown DA, Salis A, Breit SN. Anorexia-cachexia and obesity treatment may be two sides of the same coin: role of the TGF-b superfamily cytokine MIC-1/GDF15. Int J Obes. (2016) 40:193-7. doi: 10.1038/ijo.2015.242

37. Borner T, Arnold M, Ruud J, Breit SN, Langhans W, Lutz TA, et al. Anorexia-cachexia syndrome in hepatoma tumour-bearing rats requires the area postrema but not vagal afferents and is paralleled by increased MIC-1/GDF15. J Cachexia Sarcopenia Musc. (2017) 8:417-27. doi: 10.1002/jcsm.12169

38. Lerner L, Tao J, Liu Q, Nicoletti R, Feng B, Krieger B, et al. MAP3K11/GDF15 axis is a critical driver of cancer cachexia. J Cachexia Sarcopenia Musc. (2016) 7:467-82. doi: 10.1002/jcsm. 12077

39. Chrysovergis K, Wang X, Kosak J, Lee SH, Kim JS, Foley JF, et al. NAG-1/GDF-15 prevents obesity by increasing thermogenesis, lipolysis and oxidative metabolism. Int J Obes. (2014) 38:1555-64. doi: 10.1038/ijo.2014.27

40. Tran T, Yang J, Gardner J, Xiong Y. GDF15 deficiency promotes high fat diet-induced obesity in mice. PLOS ONE. (2018) 13:e0201584. doi: 10.1371/journal.pone.0201584

41. Yang L, Chang CC, Sun Z, Madsen D, Zhu H, Padkjaer SB, et al. GFRAL is the receptor for GDF15 and is required for the anti-obesity effects of the ligand. Nat Med. (2017) 23:1158-66. doi: 10.1038/nm.4394

42. Coll AP, Chen M, Taskar P, Rimmington D, Patel S, Tadross J, et al. GDF15 mediates the effects of metformin on body weight and energy balance. Nature. (2019) 578:444-8. doi: 10.1038/s41586-019-1911-y

43. Jones JE, Cadena SM, Gong C, Wang X, Chen Z, Wang SX, et al. Supraphysiologic administration of GDF11 induces cachexia in part by upregulating GDF15. Cell Rep. (2018) 22:1522-30. doi: 10.1016/j.celrep.2018.01.044

44. Moore AG, Brown DA, Fairlie WD, Bauskin AR, Brown PK, Munier $\mathrm{ML}$, et al. The transforming growth factor-ss superfamily cytokine macrophage inhibitory cytokine-1 is present in high concentrations in the serum of pregnant women. J Clin Endocrinol Metab. (2000) 85:4781-8. doi: 10.1210/jcem.85.12.7007

45. Tong S, Marjono B, Brown DA, Mulvey S, Breit SN, Manuelpillai $\mathrm{U}$, et al. Serum concentrations of macrophage inhibitory cytokine 1 (MIC 1) as a predictor of miscarriage. Lancet. (2004) 363:129-30. doi: 10.1016/S0140-6736(03)15265-8

46. Kaitu'u-Lino TUJ, Bambang K, Onwude J, Hiscock R, Konje J, Tong S. Plasma MIC-1 and PAPP-a levels are decreased among women presenting to an early pregnancy assessment unit, have fetal viability confirmed but later miscarry. PLoS ONE. (2013) 8:e72437. doi: 10.1371/journal.pone.0072437

47. Chen Q, Wang Y, Zhao M, Hyett J, da Silva Costa F, Nie G. Serum levels of GDF15 are reduced in preeclampsia and the reduction is more profound in late-onset than early-onset cases. Cytokine. (2016) 83:226-30. doi: 10.1016/j.cyto.2016.05.002

48. Soucek K, Slabakova E, Ovesna P, Malenovska A, Kozubik A, Hampl A. Growth/differentiation factor-15 is an abundant cytokine in human seminal plasma. Hum Reprod. (2010) 25:2962-71. doi: 10.1093/humrep/deq264

49. Fejzo MS, Fasching PA, Schneider MO, Schwitulla J, Beckmann MW, Schwenke E, et al. Analysis of GDF15 and IGFBP7 in hyperemesis gravidarum support causality. Geburtshilfe Frauenheilkd. (2019) 79:382-8. doi: 10.1055/a-0830-1346

50. Kim JM, Kosak JP, Kim JK, Kissling G, Germolec DR, Zeldin DC, et al. NAG-1/GDF15 transgenic mouse has less white adipose tissue and a reduced inflammatory response. Mediat Inflamm. (2013) 2013:641851. doi: 10.1155/2013/641851

51. Wu D, Molofsky AB, Liang HE, Ricardo-Gonzalez RR, Jouihan HA, Bando JK, et al. Eosinophils sustain adipose alternatively activated 
macrophages associated with glucose homeostasis. Science. (2011) 332:2437. doi: $10.1126 /$ science. 1201475

52. Jung SB, Choi MJ, Ryu D, Yi HS, Lee SE, Chang JY, et al. Reduced oxidative capacity in macrophages results in systemic insulin resistance. Nat Commun. (2018) 9:1551. doi: 10.1038/s41467-018-03998-Z

53. Viola A, Munari F, Sanchez-Rodriguez R, Scolaro T, Castegna A. The metabolic signature of macrophage responses. Front Immunol. (2019) 10:1462. doi: 10.3389/fimmu.2019.01462

54. Nishimura S, Manabe I, Nagasaki M, Eto K, Yamashita H, Ohsugi $\mathrm{M}$, et al. CD8+ effector $\mathrm{T}$ cells contribute to macrophage recruitment and adipose tissue inflammation in obesity. Nat Med. (2009) 15:914-20. doi: 10.1038/nm.1964

55. Lumeng CN, Bodzin JL, Saltiel AR. Obesity induces a phenotypic switch in adipose tissue macrophage polarization. J Clin Invest. (2007) 117:175-84. doi: 10.1172/JCI29881

56. Lackey DE, Olefsky JM. Regulation of metabolism by the innate immune system. Nat Rev Endocrinol. (2016) 12:15-28. doi: 10.1038/nrendo.2015.189

57. Lee SE, Kang SG, Choi MJ, Jung SB, Ryu MJ, Chung HK, et al. Growth differentiation factor 15 mediates systemic glucose regulatory action of Thelper type 2 cytokines. Diabetes. (2017) 66:2774-88. doi: 10.2337/db17-0333

58. Kang YE, Kim HJ, Shong M. Regulation of systemic glucose homeostasis by T helper type 2 cytokines. Diabetes Metab J. (2019) 43:549-59. doi: $10.4093 / \mathrm{dmj} .2019 .0157$

59. Kempf T, Guba-Quint A, Torgerson J, Magnone MC, Haefliger C, Bobadilla $\mathrm{M}$, et al. Growth differentiation factor 15 predicts future insulin resistance and impaired glucose control in obese nondiabetic individuals: results from the XENDOS trial. Eur J Endocrinol. (2012) 167:671-8. doi: 10.1530/EJE-12-0466

60. Bao X, Borne Y, Muhammad IF, Nilsson J, Lind L, Melander O, et al. Growth differentiation factor 15 is positively associated with incidence of diabetes mellitus: the malmo diet and cancer-cardiovascular cohort. Diabetologia. (2019) 62:78-86. doi: 10.1007/s00125-018-4751-7

61. Berezin AE. Diabetes mellitus related biomarker: the predictive role of growth-differentiation factor-15. Diabetes Metab Syndr. (2016) 10(Suppl. 1):S154-7. doi: 10.1016/j.dsx.2015.09.016

62. Hsiao EC, Koniaris LG, Zimmers-Koniaris T, Sebald SM, Huynh TV, Lee SJ. Characterization of growth-differentiation factor 15, a transforming growth factor beta superfamily member induced following liver injury. Mol Cell Biol. (2000) 20:3742-51. doi: 10.1128/MCB.20.10.3742-375 1.2000

63. Chung HK, Kim JT, Kim HW, Kwon M, Kim SY, Shong M, et al. GDF15 deficiency exacerbates chronic alcohol- and carbon tetrachlorideinduced liver injury. Sci Rep. (2017) 7:17238. doi: 10.1038/s41598-017-1 7574-w

64. Xu J, Kimball TR, Lorenz JN, Brown DA, Bauskin AR, Klevitsky R, et al. GDF15/MIC-1 functions as a protective and antihypertrophic factor released from the myocardium in association with SMAD protein activation. Circ Res. (2006) 98:342-50. doi: 10.1161/01.RES.0000202804.8 4885.d0

65. Kempf T, Eden M, Strelau J, Naguib M, Willenbockel C, Tongers J, et al. The transforming growth factor-beta superfamily member growthdifferentiation factor-15 protects the heart from ischemia/reperfusion injury. Circ Res. (2006) 98:351-60. doi: 10.1161/01.RES.0000202805.73 038.48

66. Kempf T, Zarbock A, Widera C, Butz S, Stadtmann A, Rossaint J, et al. GDF-15 is an inhibitor of leukocyte integrin activation required for survival after myocardial infarction in mice. Nat Med. (2011) 17:581-8. doi: $10.1038 / \mathrm{nm} .2354$

67. Abulizi P, Loganathan N, Zhao D, Mele T, Zhang Y, Zwiep T, et al. Growth differentiation factor-15 deficiency augments inflammatory response and exacerbates septic heart and renal injury induced by lipopolysaccharide. Sci Rep. (2017) 7:1037. doi: 10.1038/s41598-017-00902-5

68. Luan HH, Wang A, Hilliard BK, Carvalho F, Rosen CE, Ahasic $\mathrm{AM}$, et al. GDF15 is an inflammation-induced central mediator of tissue tolerance. Cell. (2019) 178:1231-44 e1211. doi: 10.1016/j.cell. 2019.07.033

69. Wang A, Huen SC, Luan HH, Yu S, Zhang C, Gallezot JD, et al. Opposing effects of fasting metabolism on tissue tolerance in bacterial and viral inflammation. Cell. (2016) 166:1512-25 e1512. doi: $10.1016 /$ j.cell.2016.07.026
70. Zimmers TA, Jin X, Hsiao EC, McGrath SA, Esquela AF, Koniaris LG. Growth differentiation factor-15/macrophage inhibitory cytokine-1 induction after kidney and lung injury. Shock. (2005) 23:543-8.

71. Freeman CM, Martinez CH, Todt JC, Martinez FJ, Han MK, Thompson $\mathrm{DL}$, et al. Acute exacerbations of chronic obstructive pulmonary disease are associated with decreased CD4+ \& CD8 + T cells and increased growth \& differentiation factor-15 (GDF-15) in peripheral blood. Respir Res. (2015) 16:94. doi: 10.1186/s12931-015-0251-1

72. Zhang Y, Jiang M, Nouraie M, Roth MG, Tabib T, Winters S, et al. GDF15 is an epithelial-derived biomarker of idiopathic pulmonary fibrosis. Am J Physiol Lung Cell Mol Physiol. (2019) 317:L510-21. doi: 10.1152/ajplung.00062.2019

73. Lambert JR, Whitson RJ, Iczkowski KA, La Rosa FG, Smith ML, Wilson RS, et al. Reduced expression of GDF-15 is associated with atrophic inflammatory lesions of the prostate. Prostate. (2015) 75:255-65. doi: $10.1002 /$ pros. 22911

74. Tanrikulu O, Sariyildiz MA, Batmaz I, Yazmalar L, Polat N, Kaplan I, et al. Serum GDF-15 level in rheumatoid arthritis: relationship with disease activity and subclinical atherosclerosis. Acta Reumatol Port. (2017) 42:66-72.

75. Xu G, Thielen L, Chen J, Jo S, Shalev A. GDF15 is induced by T1D-associated cytokines and ER stress and promotes beta-cell apoptosis. Diabetes. 67(Suppl. 1):2109. doi: 10.2337/db18-2109-P

76. Nakayasu ES, Syed F, Tersey SA, Gritsenko MA, Mitchell HD, Chan CY, et al. Comprehensive proteomics analysis of stressed human islets identifies GDF15 as a target for type 1 diabetes intervention. Cell Metab. (2020) 31:363-74.e6. doi: 10.1016/j.cmet.2019.12.005

77. Amstad A, Coray M, Frick C, Barro C, Oechtering J, Amann M, et al. Growth-differentiation factor 15 is increased in stable multiple sclerosis. Neurol Neuroimmunol Neuroinflamm. (2020) 7:e675. doi: 10.1212/NXI.0000000000000675

78. Li C, Wang J, Kong J, Tang J, Wu Y, Xu E, et al. GDF15 promotes EMT and metastasis in colorectal cancer. Oncotarget. (2016) 7:860-72. doi: 10.18632/oncotarget.6205

79. Wang X, Yang Z, Tian H, Li Y, Li M, Zhao W, et al. Circulating MIC-1/GDF15 is a complementary screening biomarker with CEA and correlates with liver metastasis and poor survival in colorectal cancer. Oncotarget. (2017) 8:24892-901. doi: 10.18632/oncotarget.15279

80. Zhao D, Wang X, Zhang W. GDF15 predict platinum response during first-line chemotherapy and can act as a complementary diagnostic serum biomarker with CA125 in epithelial ovarian cancer. BMC Cancer. (2018) 18:328. doi: 10.1186/s12885-018-4246-4

81. Liu YN, Wang XB, Wang T, Zhang C, Zhang KP, Zhi XY, et al. Macrophage inhibitory cytokine-1 as a novel diagnostic and prognostic biomarker in stage I and II nonsmall cell lung cancer. Chin Med J. (2016) 129:2026-32. doi: 10.4103/0366-6999.189052

82. Hogendorf P, Durczynski A, Skulimowski A, Kumor A, Poznanska G, Strzelczyk J. Growth differentiation factor (GDF-15) concentration combined with Ca125 levels in serum is superior to commonly used cancer biomarkers in differentiation of pancreatic mass. Cancer Biomark. (2018) 21:505-11. doi: 10.3233/CBM-170203

83. Gronberg H, Adolfsson J, Aly M, Nordstrom T, Wiklund P, Brandberg $\mathrm{Y}$, et al. Prostate cancer screening in men aged 50-69 years (STHLM3): a prospective population-based diagnostic study. Lancet Oncol. (2015) 16:1667-76. doi: 10.1016/S1470-2045(15)00361-7

84. Li J, Veltri RW, Yuan Z, Christudass CS, Mandecki W. Macrophage inhibitory cytokine 1 biomarker serum immunoassay in combination with PSA is a more specific diagnostic tool for detection of prostate cancer. PLoS ONE. (2015) 10:e0122249. doi: 10.1371/journal.pone.0122249

85. Bansal N, Kumar D, Gupta A, Chandra D, Sankhwar SN, Mandhani A. Relevance of MIC-1 in the era of PSA as a serum based predictor of prostate cancer: a critical evaluation. Sci Rep. (2017) 7:16824. doi: 10.1038/s41598-017-17207-2

86. Mehta RS, Song M, Bezawada N, Wu K, Garcia-Albeniz X, Morikawa $\mathrm{T}$, et al. A prospective study of macrophage inhibitory cytokine-1 (MIC1/GDF15) and risk of colorectal cancer. J Natl Cancer Inst. (2014) 106:dju016. doi: 10.1093/jnci/dju016

87. Mehta RS, Chong DQ, Song M, Meyerhardt JA, Ng K, Nishihara R, et al. Association between plasma levels of macrophage inhibitory cytokine-1 before diagnosis of colorectal cancer and mortality. Gastroenterology. (2015) 149:614-22. doi: 10.1053/j.gastro.2015.05.038 
88. Baek SJ, Okazaki R, Lee SH, Martinez J, Kim JS, Yamaguchi K, et al. Nonsteroidal anti-inflammatory drug-activated gene-1 over expression in transgenic mice suppresses intestinal neoplasia. Gastroenterology. (2006) 131:1553-60. doi: 10.1053/j.gastro.2006.09.015

89. Baek KE, Yoon SR, Kim JT, Kim KS, Kang SH, Yang Y, et al. Upregulation and secretion of macrophage inhibitory cytokine-1 (MIC-1) in gastric cancers. Clin Chim Acta. (2009) 401:128-33. doi: 10.1016/j.cca.2008.12.008

90. Blanco-Calvo M, Tarrio N, Reboredo M, Haz-Conde M, Garcia J, Quindos M, et al. Circulating levels of GDF15, MMP7 and miR-200c as a poor prognostic signature in gastric cancer. Fut Oncol. (2014) 10:1187-202. doi: $10.2217 /$ fon. 13.263

91. Ishige $T$, Nishimura $M$, Satoh $M$, Fujimoto $M$, Fukuyo $M$, Semba $T$, et al. Combined secretomics and transcriptomics revealed cancer-derived GDF15 is involved in diffuse-type gastric cancer progression and fibroblast activation. Sci Rep. (2016) 6:21681-21681. doi: 10.1038/srep21681

92. Liu X, Chi X, Gong Q, Gao L, Niu Y, Chi X, et al. Association of serum level of growth differentiation factor 15 with liver cirrhosis and hepatocellular carcinoma. PLoS ONE. (2015) 10:e0127518. doi: 10.1145/2818302

93. Traeger L, Ellermann I, Wiethoff H, Ihbe J, Gallitz I, Eveslage M, et al. Serum Hepcidin and GDF-15 levels as prognostic markers in urothelial carcinoma of the upper urinary tract and renal cell carcinoma. BMC Cancer. (2019) 19:74. doi: 10.1186/s12885-019-5278-0

94. Weide B, Schafer T, Martens A, Kuzkina A, Uder L, Noor S, et al. High GDF-15 serum levels independently correlate with poorer overall survival of patients with tumor-free stage III and unresectable stage IV melanoma. $J$ Invest Dermatol. (2016) 136:2444-52. doi: 10.1016/j.jid.2016.07.016

95. Windrichova J, Fuchsova R, Kucera R, Topolcan O, Fiala O, Finek J, et al. MIC1/GDF15 as a bone metastatic disease biomarker. Anticancer Res. (2017) 37:1501-5. doi: 10.21873/anticanres.11477

96. Tanno T, Lim Y, Wang Q, Chesi M, Bergsagel PL, Matthews G, et al. Growth differentiating factor 15 enhances the tumor-initiating and selfrenewal potential of multiple myeloma cells. Blood. (2014) 123:725-33. doi: 10.1182/blood-2013-08-524025

97. Westhrin M, Moen SH, Holien T, Mylin AK, Heickendorff L, Olsen $\mathrm{OE}$, et al. Growth differentiation factor 15 (GDF15) promotes osteoclast differentiation and inhibits osteoblast differentiation and high serum GDF15 levels are associated with multiple myeloma bone disease. Haematologica. (2015) 100:e511-14. doi: 10.3324/haematol.2015.124511

98. Schiegnitz E, Kammerer PW, Koch FP, Kruger M, Berres M, AlNawas B. GDF 15 as an anti-apoptotic, diagnostic and prognostic marker in oral squamous cell carcinoma. Oral Oncol. (2012) 48:608-14. doi: 10.1016/j.oraloncology.2012.01.020

99. Zhou Z, Li W, Song Y, Wang L, Zhang K, Yang J, et al. Growth differentiation factor-15 suppresses maturation and function of dendritic cells and inhibits tumor-specific immune response. PLOS ONE. (2013) 8:e78618. doi: 10.1371/journal.pone.0078618

100. Brown DA, Lindmark F, Stattin P, Balter K, Adami HO, Zheng SL, et al. Macrophage inhibitory cytokine 1: a new prognostic marker in prostate cancer. Clin Cancer Res. (2009) 15:6658-64. doi: 10.1158/1078-0432.CCR-08-3126

101. Suesskind D, Schatz A, Schnichels S, Coupland SE, Lake SL, Wissinger B, et al. GDF-15: a novel serum marker for metastases in uveal melanoma patients. Graefes Arch Clin Exp Ophthalmol. (2012) 250:887-95. doi: 10.1007/s00417-011-1786-6

102. Staff AC, Bock AJ, Becker C, Kempf T, Wollert KC, Davidson B. Growth differentiation factor-15 as a prognostic biomarker in ovarian cancer. Gynecol Oncol. (2010) 118:237-43. doi: 10.1016/j.ygyno.2010. 05.032

103. Zhang Y, Hua W, Niu LC, Li SM, Wang YM, Shang L, et al. Elevated growth differentiation factor 15 expression predicts poor prognosis in epithelial ovarian cancer patients. Tumour Biol. (2016) 37:9423-31. doi: 10.1007/s13277-015-4699-x

104. Staff AC, Trovik J, Eriksson AG, Wik E, Wollert KC, Kempf T, et al. Elevated plasma growth differentiation factor- 15 correlates with lymph node metastases and poor survival in endometrial cancer. Clin Cancer Res. (2011) 17:4825-33. doi: 10.1158/1078-0432.CCR-11-0715

105. Wang XB, Jiang XR, Yu XY, Wang L, He S, Feng FY, et al. Macrophage inhibitory factor 1 acts as a potential biomarker in patients with esophageal squamous cell carcinoma and is a target for antibody-based therapy. Cancer Sci. (2014) 105:176-85. doi: 10.1111/cas.12331
106. Shnaper S, Desbaillets I, Brown DA, Murat A, Migliavacca E, Schluep M, et al. Elevated levels of MIC-1/GDF15 in the cerebrospinal fluid of patients are associated with glioblastoma and worse outcome. Int J Cancer. (2009) 125:2624-30. doi: 10.1002/ijc.24639

107. Codo P, Weller M, Kaulich K, Schraivogel D, Silginer M, Reifenberger G, et al. Control of glioma cell migration and invasiveness by GDF-15. Oncotarget. (2016) 7:7732-46. doi: 10.18632/oncotarget.6816

108. Ratnam NM, Peterson JM, Talbert EE, Ladner KJ, Rajasekera PV, Schmidt $\mathrm{CR}$, et al. NF-kappaB regulates GDF-15 to suppress macrophage surveillance during early tumor development. J Clin Invest. (2017) 127:3796-809. doi: 10.1172/JCI91561

109. Peake BF, Eze SM, Yang L, Castellino RC, Nahta R. Growth differentiation factor 15 mediates epithelial mesenchymal transition and invasion of breast cancers through IGF-1R-FoxM1 signaling. Oncotarget. (2017) 8:94393-406. doi: 10.18632/oncotarget.21765

110. Li C, Wang X, Casal I, Wang J, Li P, Zhang W, et al. Growth differentiation factor 15 is a promising diagnostic and prognostic biomarker in colorectal cancer. J Cell Mol Med. (2016) 20:1420-6. doi: 10.1111/jcmm.12830

111. Vocka M, Langer D, Fryba V, Petrtyl J, Hanus T, Kalousova M, et al. Growth/differentiation factor 15 (GDF-15) as new potential serum marker in patients with metastatic colorectal cancer. Cancer Biomark. (2018) 21:86974. doi: 10.3233/CBM-170792

112. Song M, Mehta RS, Wu K, Fuchs CS, Ogino S, Giovannucci EL, et al. Plasma inflammatory markers and risk of advanced colorectal adenoma in women. Cancer Prev Res. (2016) 9:27-34. doi: 10.1158/1940-6207.CAPR15-0307

113. Brown DA, Ward RL, Buckhaults P, Liu T, Romans KE, Hawkins NJ, et al. MIC-1 serum level and genotype: associations with progress and prognosis of colorectal carcinoma. Clin Cancer Res. (2003) 9:2642-50.

114. Wallin U, Glimelius B, Jirstrom K, Darmanis S, Nong RY, Ponten F, et al. Growth differentiation factor 15: a prognostic marker for recurrence in colorectal cancer. Br J Cancer. (2011) 104:1619-27. doi: 10.1038/bjc.20 11.112

115. Engerud H, Hope K, Berg HF, Fasmer KE, Tangen IL, Haldorsen IS, et al. Plasma growth differentiation factor-15 is an independent marker for aggressive disease in endometrial cancer. PLoS ONE. (2019) 14:e0210585. doi: 10.1371/journal.pone.0210585

116. Lu Z, Yang L, Yu J, Lu M, Zhang X, Li J, et al. Change of body weight and macrophage inhibitory cytokine-1 during chemotherapy in advanced gastric cancer: what is their clinical significance? PLoS ONE. (2014) 9:e88553. doi: 10.1371/journal.pone.0088553

117. Yang CZ, Ma J, Luo QQ, Neskey DM, Zhu DW, Liu Y, et al. Elevated level of serum growth differentiation factor 15 is associated with oral leukoplakia and oral squamous cell carcinoma. J Oral Pathol Med. (2014) 43:28-34. doi: 10.1111 /jop. 12091

118. Nyakas M, Aamdal E, Jacobsen KD, Guren TK, Aamdal S, Hagene KT, et al. Prognostic biomarkers for immunotherapy with ipilimumab in metastatic melanoma. Clin Exp Immunol. (2019) 197:74-82. doi: 10.1111/cei. 13283

119. Huh SJ, Chung CY, Sharma A, Robertson GP. Macrophage inhibitory cytokine-1 regulates melanoma vascular development. Am J Pathol. (2010) 176:2948-57. doi: 10.2353/ajpath.2010.090963

120. Boyle GM, Pedley J, Martyn AC, Banducci KJ, Strutton GM, Brown DA, et al. Macrophage inhibitory cytokine-1 is overexpressed in malignant melanoma and is associated with tumorigenicity. J Invest Dermatol. (2009) 129:383-91. doi: $10.1038 /$ jid.2008.270

121. Corre J, Labat E, Espagnolle N, Hebraud B, Avet-Loiseau H, Roussel $M$, et al. Bioactivity and prognostic significance of growth differentiation factor GDF15 secreted by bone marrow mesenchymal stem cells in multiple myeloma. Cancer Res. (2012) 72:1395-406. doi: 10.1158/0008-5472.CAN-11-0188

122. Lu X, He X, Su J, Wang J, Liu X, Xu K, et al. EZH2-mediated epigenetic suppression of GDF15 predicts a poor prognosis and regulates cell proliferation in non-small-cell lung cancer. Mol Ther Nucleic Acids. (2018) 12:309-18. doi: 10.1016/j.omtn.2018.05.016

123. Fisher OM, Levert-Mignon AJ, Lord SJ, Lee-Ng KK, Botelho NK, Falkenback D, et al. MIC-1/GDF15 in Barrett's oesophagus and oesophageal adenocarcinoma. Br J Cancer. (2015) 112:1384-91. doi: 10.1038/bjc.2015.100

124. Lima CA, Jammal MP, Martins-Filho A, Silveira TP, Micheli DC, TavaresMurta BM, et al. Stromal growth differentiation factor 15 and its 
association with ovarian cancer. Gynecol Obstet Invest. (2018) 83:35-9. doi: 10.1159/000473891

125. Martin Boegemann FJW. GDF15 and hepcidin as prognostic factors in patients with prostate cancer. J Mol Biomark Diagn. (2014) 5:6. doi: 10.4172/2155-9929.1000199

126. Song J, Merbs SL, Sokoll LJ, Chan DW, Zhang Z. A multiplex immunoassay of serum biomarkers for the detection of uveal melanoma. Clin Proteomics. (2019) 16:10. doi: 10.1186/s12014-019-9230-8

127. Arfsten H, Cho A, Freitag C, Raderer M, Goliasch G, Bartko PE, et al. GDF15 in solid vs non-solid treatment-naive malignancies. Eur J Clin Invest. (2019) 49:e13168. doi: 10.1111/eci.13168

128. Wang J, Li W, Wang Y, Li C, Ding M, Zhang H, et al. The H6D genetic variation of GDF15 is associated with genesis, progress and prognosis in colorectal cancer. Pathol Res Pract. (2015) 211:845-50. doi: 10.1016/j.prp.2015.08.004

129. Lindmark F, Zheng SL, Wiklund F, Bensen J, Balter KA, Chang B, et al. H6D polymorphism in macrophage-inhibitory cytokine-1 gene associated with prostate cancer. J Natl Cancer Inst. (2004) 96:1248-54. doi: 10.1093/jnci/djh227

130. Hayes VM, Severi G, Southey MC, Padilla EJ, English DR, Hopper JL, et al. Macrophage inhibitory cytokine-1 H6D polymorphism, prostate cancer risk, and survival. Cancer Epidemiol Biomark Prev. (2006) 15:1223-5. doi: 10.1158/1055-9965.EPI-06-0063

131. Tsai VW, Manandhar R, Jorgensen SB, Lee-Ng KK, Zhang HP, Marquis CP, et al. The anorectic actions of the TGFbeta cytokine MIC-1/GDF15 require an intact brainstem area postrema and nucleus of the solitary tract. PLoS ONE. (2014) 9:e100370. doi: 10.1371/journal.pone.0100370

132. Dunn GP, Bruce AT, Ikeda H, Old LJ, Schreiber RD. Cancer immunoediting: from immunosurveillance to tumor escape. Nat Immunol. (2002) 3:991-8. doi: $10.1038 /$ ni1102-991

133. Chen DS, Mellman I. Elements of cancer immunity and the cancer-immune set point. Nature. (2017) 541:321-30. doi: 10.1038/nature21349

134. Hanahan D, Weinberg RA. Hallmarks of cancer: the next generation. Cell. (2011) 144:646-74. doi: 10.1016/j.cell.2011.02.013

135. Galon J, Costes A, Sanchez-Cabo F, Kirilovsky A, Mlecnik B, LagorcePagès C, et al. Type, density, and location of immune cells within human colorectal tumors predict clinical outcome. Science. (2006) 313:1960-4. doi: 10.1126/science.1129139

136. Fridman WH, Zitvogel L, Sautès-Fridman C, Kroemer G. The immune contexture in cancer prognosis and treatment. Nat Rev Clin Oncol. (2017) 14:717-34. doi: 10.1038/nrclinonc.2017.101

137. Becht E, Giraldo NA, Germain C, de Reynies A, Laurent-Puig P, ZucmanRossi J, et al. Immune contexture, immunoscore, and malignant cell molecular subgroups for prognostic and theranostic classifications of cancers. Adv Immunol. (2016) 130:95-190. doi: 10.1016/bs.ai.2015.12.002

138. Angell HK, Bruni D, Barrett JC, Herbst R, Galon J. The immunoscore: colon cancer and beyond. Clin. Cancer Res. (2019) 26:332-9. doi: 10.1158/1078-0432.CCR-18-1851

139. Sautès-Fridman C, Petitprez F, Calderaro J, Fridman WH. Tertiary lymphoid structures in the era of cancer immunotherapy. Nat Rev Cancer. (2019) 19:307-25. doi: 10.1038/s41568-019-0144-6

140. Roth P, Junker M, Tritschler I, Mittelbronn M, Dombrowski Y, Breit SN, et al. GDF-15 contributes to proliferation and immune escape of malignant gliomas. Clin Cancer Res. (2010) 16:3851-9. doi: 10.1158/1078-0432.CCR-10-0705

141. Ago T, Sadoshima J. GDF15, a cardioprotective TGFbeta superfamily protein. Circ Res. (2006) 98:294-7. doi: 10.1161/01.RES.0000207919.83894.9d

142. Artz A, Butz S, Vestweber D. GDF-15 inhibits integrin activation and mouse neutrophil recruitment through the ALK-5/TGF-betaRII heterodimer. Blood. (2016) 128:529-41. doi: 10.1182/blood-2016-01-696617

143. Li Z, Wang B, Wu X, Cheng S-Y, Paraoan L, Zhou J. Identification, expression and functional characterization of the GRAL gene. J Neurochem. (2005) 95:361-76. doi: 10.1111/j.1471-4159.2005.03372.x

144. Muralidharan AR, Maddala R, Skiba NP, Rao PV. Growth differentiation factor-15-induced contractile activity and extracellular matrix production in human trabecular meshwork cells. Invest Ophthalmol Vis Sci. (2016) 57:6482-95. doi: 10.1167/iovs.16-20671

145. Blanchette-Farra N, Kita D, Konstorum A, Tesfay L, Lemler D, Hegde P, et al. Contribution of three-dimensional architecture and tumor-associated fibroblasts to hepcidin regulation in breast cancer. Oncogene. (2018) 37:4013-32. doi: 10.1038/s41388-018-0243-y

146. Kim KK, Lee JJ, Yang Y, You KH, Lee JH. Macrophage inhibitory cytokine-1 activates AKT and ERK-1/2 via the transactivation of ErbB2 in human breast and gastric cancer cells. Carcinogenesis. (2008) 29:704-12. doi: 10.1093/carcin/bgn031

147. Joshi JP, Brown NE, Griner SE, Nahta R. Growth differentiation factor 15 (GDF15)-mediated HER2 phosphorylation reduces trastuzumab sensitivity of HER2-overexpressing breast cancer cells. Biochem Pharmacol. (2011) 82:1090-9. doi: 10.1016/j.bcp.2011.07.082

148. Donnelly SM, Paplomata E, Peake BM, Sanabria E, Chen Z, Nahta R. P38 MAPK contributes to resistance and invasiveness of HER2overexpressing breast cancer. Curr Med Chem. (2014) 21:501-10. doi: 10.2174/0929867320666131119155023

149. Park YJ, Lee H, Lee JH. Macrophage inhibitory cytokine-1 transactivates ErbB family receptors via the activation of Src in SK-BR-3 human breast cancer cells. BMB Rep. (2010) 43:91-6. doi: 10.5483/BMBRep.2010.43.2.091

150. Wang T, Mao B, Cheng C, Zou Z, Gao J, Yang Y, et al. YAP promotes breast cancer metastasis by repressing growth differentiation factor15. Biochim Biophys Acta Mol Basis Dis. (2018) 1864(Pt. A):1744-53. doi: 10.1016/j.bbadis.2018.02.020

151. Li S, Ma YM, Zheng PS, Zhang P. GDF15 promotes the proliferation of cervical cancer cells by phosphorylating AKT1 and Erk1/2 through the receptor ErbB2. J Exp Clin Cancer Res. (2018) 37:80. doi: 10.1186/s13046-018-0744-0

152. Cekanova M, Lee SH, Donnell RL, Sukhthankar M, Eling TE, Fischer $\mathrm{SM}$, et al. Nonsteroidal anti-inflammatory drug-activated gene-1 expression inhibits urethane-induced pulmonary tumorigenesis in transgenic mice. Cancer Prev Res. (2009) 2:450-8. doi: 10.1158/1940-6207.CAPR-09-0057

153. Kim CH, Kim MY, Moon JY, Hwang JW, Lee SY, Joo YM, et al. Implication of NAG-1 in synergistic induction of apoptosis by combined treatment of sodium salicylate and PI3K/MEK1/2 inhibitors in A549 human lung adenocarcinoma cells. Biochem Pharmacol. (2008) 75:1751-60. doi: 10.1016/j.bcp.2008.02.002

154. Zhang Y, Wang X, Zhang M, Zhang Z, Jiang L, Li L. GDF15 promotes epithelial-to-mesenchymal transition in colorectal. Artif Cells Nanomed Biotechnol. (2018) 46:652-8. doi: 10.1080/21691401.2018.1466146

155. Yamaguchi K, Lee SH, Eling TE, Baek SJ. Identification of nonsteroidal antiinflammatory drug-activated gene (NAG-1) as a novel downstream target of phosphatidylinositol 3-kinase/AKT/GSK-3beta pathway. J Biol Chem. (2004) 279:49617-23. doi: 10.1074/jbc.M408796200

156. Chen SJ, Karan D, Johansson SL, Lin FF, Zeckser J, Singh AP, et al. Prostatederived factor as a paracrine and autocrine factor for the proliferation of androgen receptor-positive human prostate cancer cells. Prostate. (2007) 67:557-71. doi: 10.1002/pros.20551

157. Tsui KH, Chang YL, Feng TH, Chung LC, Lee TY, Chang PL, et al. Growth differentiation factor-15 upregulates interleukin- 6 to promote tumorigenesis of prostate carcinoma PC-3 cells. J Mol Endocrinol. (2012) 49:153-63. doi: 10.1530/JME-11-0149

158. Bruzzese F, Hagglof C, Leone A, Sjoberg E, Roca MS, Kiflemariam $\mathrm{S}$, et al. Local and systemic protumorigenic effects of cancerassociated fibroblast-derived GDF15. Cancer Res. (2014) 74:3408-17. doi: 10.1158/0008-5472.CAN-13-2259

159. Senapati S, Rachagani S, Chaudhary K, Johansson SL, Singh RK, Batra SK. Overexpression of macrophage inhibitory cytokine-1 induces metastasis of human prostate cancer cells through the FAK-RhoA signaling pathway. Oncogene. (2010) 29:1293-302. doi: 10.1038/onc.2009.420

160. Han M, Dai D, Yousafzai NA, Wang F, Wang H, Zhou Q, et al. CXXC4 activates apoptosis through up-regulating GDF15 in gastric cancer. Oncotarget. (2017) 8:103557-67. doi: 10.18632/oncotarget. 21581

161. Si Y, Liu X, Cheng M, Wang M, Gong Q, Yang Y, et al. Growth differentiation factor 15 is induced by hepatitis $C$ virus infection and regulates hepatocellular carcinoma-related genes. PLOS ONE. (2011) 6:e19967. doi: 10.1371/journal.pone.0019967

162. Shin DY, Kim GY, Kim ND, Jung JH, Kim SK, Kang HS, et al. Induction of apoptosis by pectenotoxin-2 is mediated with the induction of DR4/DR5, Egr-1 and NAG-1, activation of caspases and modulation of the Bcl-2 family in p53-deficient Hep3B hepatocellular carcinoma cells. Oncol Rep. (2008) 19:517-26. doi: 10.3892/or.19.2.517 
163. Auyeung KK, Ko JK. Coptis chinensis inhibits hepatocellular carcinoma cell growth through nonsteroidal anti-inflammatory drug-activated gene activation. Int J Mol Med. (2009) 24:571-7. doi: 10.3892/ijmm_00000267

164. Zhang X, Kang Y, Huo T, Tao R, Wang X, Li Z, et al. GL-V9 induced upregulation and mitochondrial localization of NAG-1 associates with ROS generation and cell death in hepatocellular carcinoma cells. Free Radic Biol Med. (2017) 112:49-59. doi: 10.1016/j.freeradbiomed.2017.07.011

165. Xu Q, Xu HX, Li JP, Wang S, Fu Z, Jia J, et al. Growth differentiation factor 15 induces growth and metastasis of human liver cancer stem-like cells via AKT/GSK-3beta/beta-catenin signaling. Oncotarget. (2017) 8:16972-87. doi: 10.18632/oncotarget.15216

166. Kim KH, Park SH, Do KH, Kim J, Choi KU, Moon Y. NSAIDactivated gene 1 mediates pro-inflammatory signaling activation and paclitaxel chemoresistance in type I human epithelial ovarian cancer stem-like cells. Oncotarget. (2016) 7:72148-66. doi: 10.18632/oncotarget. 12355

167. Griner SE, Joshi JP, Nahta R. Growth differentiation factor 15 stimulates rapamycin-sensitive ovarian cancer cell growth and invasion. Biochem Pharmacol. (2013) 85:46-58. doi: 10.1016/j.bcp.2012.10.007

168. Meier JC, Haendler B, Seidel H, Groth P, Adams R, Ziegelbauer K, et al. Knockdown of platinum-induced growth differentiation factor 15 abrogates p27-mediated tumor growth delay in the chemoresistant ovarian cancer model A2780cis. Cancer Med. (2015) 4:253-67. doi: 10.1002/cam4.354

169. Yang CZ, Ma J, Zhu DW, Liu Y, Montgomery B, Wang LZ, et al. GDF15 is a potential predictive biomarker for TPF induction chemotherapy and promotes tumorigenesis and progression in oral squamous cell carcinoma. Ann Oncol. (2014) 25:1215-22. doi: 10.1093/annonc/mdu120

170. Schiegnitz E, Kammerer PW, Rode K, Schorn T, Brieger J, Al-Nawas B. Growth differentiation factor 15 as a radiation-induced marker in oral carcinoma increasing radiation resistance. J Oral Pathol Med. (2016) 45:63-9. doi: 10.1111/jop.12323

171. Li YL, Chang JT, Lee LY, Fan KH, Lu YC, Li YC, et al. GDF15 contributes to radioresistance and cancer stemness of head and neck cancer by regulating cellular reactive oxygen species via a SMAD-associated signaling pathway. Oncotarget. (2017) 8:1508-28. doi: 10.18632/oncotarget.13649

172. Kang SU, Shin YS, Hwang HS, Baek SJ, Lee SH, Kim CH. Tolfenamic acid induces apoptosis and growth inhibition in head and neck cancer: involvement of NAG-1 expression. PLoS ONE. (2012) 7:e34988. doi: 10.1371/journal.pone.0034988

173. Ji H, Lu HW, Li YM, Lu L, Wang JL, Zhang YF, et al. Twist promotes invasion and cisplatin resistance in pancreatic cancer cells through growth differentiation factor 15. Mol Med Rep. (2015) 12:3841-8. doi: $10.3892 / \mathrm{mmr} .2015 .3867$

174. Springer TA, Dustin ML. Integrin inside-out signaling and the immunological synapse. Curr Opin Cell Biol. (2012) 24:107-15. doi: 10.1016/j.ceb.2011.10.004

175. Zhang Y, Zhang G, Liu Y, Chen R, Zhao D, McAlister V, et al. GDF15 Regulates malat-1 circular RNA and inactivates NFKB signaling leading to immune tolerogenic DCs for preventing alloimmune rejection in heart transplantation. Front Immunol. (2018) 9:2407. doi: 10.3389/fimmu.2018.02407

176. Husaini Y, Qiu MR, Lockwood GP, Luo XW, Shang P, Kuffner T, et al. Macrophage inhibitory cytokine-1 (MIC-1/GDF15) slows cancer development but increases metastases in TRAMP prostate cancer prone mice. PLoS ONE. (2012) 7:e43833. doi: 10.1371/journal.pone.0043833

177. Liu Q, Tong D, Liu G, Gao J, Wang LA, Xu J, et al. Metformin inhibits prostate cancer progression by targeting tumor-associated inflammatory infiltration. Clin Cancer Res. (2018) 24:5622-34. doi: 10.1158/1078-0432.CCR-18-0420

178. Kido LA, de Almeida Lamas C, Marostica MRJr, Cagnon VHA. Transgenic adenocarcinoma of the mouse prostate (TRAMP) model: a good alternative to study PCa progression and chemoprevention approaches. Life Sci. (2019) 217:141-7. doi: 10.1016/j.lfs.2018.12.002

179. Shah AH, Tabayoyong WB, Kundu SD, Kim SJ, Van Parijs L, Liu VC, et al. Suppression of tumor metastasis by blockade of transforming growth factor beta signaling in bone marrow cells through a retroviral-mediated gene therapy in mice. Cancer Res. (2002) 62:7135-8.
180. Street SE, Cretney E, Smyth MJ. Perforin and interferon-gamma activities independently control tumor initiation, growth, and metastasis. Blood. (2001) 97:192-7. doi: 10.1182/blood.V97.1.192

181. Senovilla L, Vacchelli E, Galon J, Adjemian S, Eggermont A, Fridman WH, et al. Trial watch: prognostic and predictive value of the immune infiltrate in cancer. Oncoimmunology. (2012) 1:1323-43. doi: 10.4161/onci.22009

182. Lopez-Soto A, Gonzalez S, Smyth MJ, Galluzzi L. Control of metastasis by NK cells. Cancer Cell. (2017) 32:135-54. doi: 10.1016/j.ccell.2017.06.009

183. Gonzalez H, Robles I, Werb Z. Innate and acquired immune surveillance in the postdissemination phase of metastasis. FEBS J. (2018) 285:654-64. doi: $10.1111 /$ febs. 14325

184. Selander KS, Brown DA, Sequeiros GB, Hunter M, Desmond R, Parpala T, et al. Serum macrophage inhibitory cytokine-1 concentrations correlate with the presence of prostate cancer bone metastases. Cancer Epidemiol Biomark Prev. (2007) 16:532-7. doi: 10.1158/1055-9965.EPI-06-0841

185. Wollert KC, Kempf T, Giannitsis E, Bertsch T, Braun SL, Maier H, et al. An automated assay for growth differentiation factor 15. J Appl Lab Med. (2017) 1:510-21. doi: 10.1373/jalm.2016.022376

186. Chen DS, and Mellman I. Oncology meets immunology: the cancerimmunity cycle. Immunity. (2013) 39:1-10. doi: 10.1016/j.immuni. 2013.07.012

187. Tumeh PC, Harview CL, Yearley JH, Shintaku IP, Taylor EJ, Robert L, et al. $\mathrm{PD}-1$ blockade induces responses by inhibiting adaptive immune resistance. Nature. (2014) 515:568-71. doi: 10.1038/nature13954

188. Lu S, Stein JE, Rimm DL, Wang DW, Bell JM, Johnson DB, et al. Comparison of biomarker modalities for predicting response to $\mathrm{PD}-1 / \mathrm{PD}-\mathrm{L} 1$ checkpoint blockade: a systematic review and meta-analysis. JAMA Oncol. (2019) 5:1195-1204. doi: 10.1001/jamaoncol.2019.1549

189. Yost KE, Satpathy AT, Wells DK, Qi Y, Wang C, Kageyama R, et al. Clonal replacement of tumor-specific T cells following PD-1 blockade. Nat Med. (2019) 25:1251-9. doi: 10.1038/s41591-019-0522-3

190. Bonaventura P, Shekarian T, Alcazer V, Valladeau-Guilemond J, Valsesia-Wittmann S, Amigorena S, et al. Cold tumors: a therapeutic challenge for immunotherapy. Front Immunol. (2019) 10:168. doi: 10.3389/fimmu.2019.00168

191. Scott AC, Dündar F, Zumbo P, Chandran SS, Klebanoff CA, Shakiba M, et al. TOX is a critical regulator of tumour-specific T cell differentiation. Nature. (2019) 571:270-4. doi: 10.1038/s41586-019-1324-y

192. Melief CJM, van Hall T, Arens R, Ossendorp F, van der Burg SH. Therapeutic cancer vaccines. J Clin Invest. (2015) 125:3401-12. doi: 10.1172/JCI80009

193. Mardiana S, Solomon BJ, Darcy PK, Beavis PA. Supercharging adoptive T cell therapy to overcome solid tumor-induced immunosuppression. Sci Transl Med. (2019) 11:eaaw2293. doi: 10.1126/scitranslmed.aaw2293

194. Havel JJ, Chowell D, Chan TA. The evolving landscape of biomarkers for checkpoint inhibitor immunotherapy. Nat Rev Cancer. (2019) 19:133-50. doi: 10.1038/s41568-019-0116-x

195. Bilen MA, Shabto JM, Martini DJ, Liu Y, Lewis C, Collins H, et al. Sites of metastasis and association with clinical outcome in advanced stage cancer patients treated with immunotherapy. BMC Cancer. (2019) 19:857. doi: 10.1186/s12885-019-6073-7

196. Komiya T, Huang CH. Updates in the clinical development of epacadostat and other indoleamine 2,3-dioxygenase 1 inhibitors (IDO1) for human cancers. Front Oncol. (2018) 8:423. doi: 10.3389/fonc.2018.00423

197. Gubin MM, Zhang X, Schuster H, Caron E, Ward JP, Noguchi T, et al. Checkpoint blockade cancer immunotherapy targets tumour-specific mutant antigens. Nature. (2014) 515:577-81. doi: 10.1038/nature13988

Conflict of Interest: WF and IM are scientific advisors to Catalym, a biotech company which develops antibodies to GDF-15; JW is a co-founder of Catalym.

Copyright (c) 2020 Wischhusen, Melero and Fridman. This is an open-access article distributed under the terms of the Creative Commons Attribution License (CC BY). The use, distribution or reproduction in other forums is permitted, provided the original author(s) and the copyright owner(s) are credited and that the original publication in this journal is cited, in accordance with accepted academic practice. No use, distribution or reproduction is permitted which does not comply with these terms. 